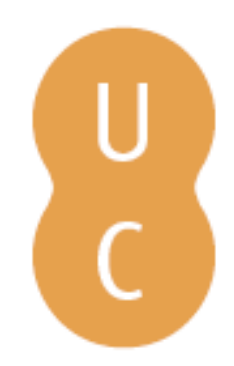

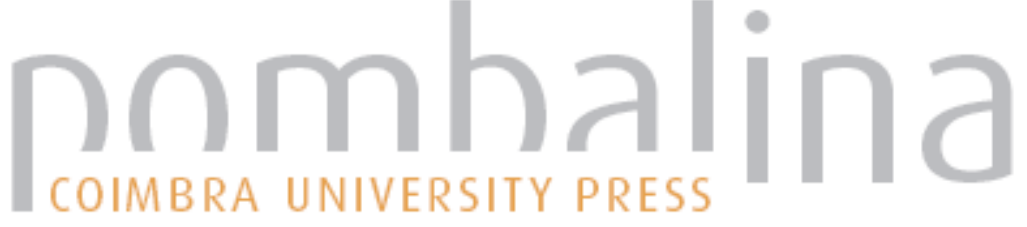

\section{ASH (Auditoria do Sistema Humano): modelos de qualidade e avaliação organizacional}
Autor(es):
Quijano de Arana, Santiago D. de
Publicado por: Imprensa da Universidade de Coimbra
URL
persistente:
URI:http://hdl.handle.net/10316.2/32725
DOI:
DOI:http://dx.doi.org/10.14195/978-989-26-0452-7_8
Accessed : $\quad$ 26-Apr-2023 10:50:30

A navegação consulta e descarregamento dos títulos inseridos nas Bibliotecas Digitais UC Digitalis, UC Pombalina e UC Impactum, pressupõem a aceitação plena e sem reservas dos Termos e Condições de Uso destas Bibliotecas Digitais, disponíveis em https://digitalis.uc.pt/pt-pt/termos.

Conforme exposto nos referidos Termos e Condições de Uso, o descarregamento de títulos de acesso restrito requer uma licença válida de autorização devendo o utilizador aceder ao(s) documento(s) a partir de um endereço de IP da instituição detentora da supramencionada licença.

Ao utilizador é apenas permitido o descarregamento para uso pessoal, pelo que o emprego do(s) título(s) descarregado(s) para outro fim, designadamente comercial, carece de autorização do respetivo autor ou editor da obra.

Na medida em que todas as obras da UC Digitalis se encontram protegidas pelo Código do Direito de Autor e Direitos Conexos e demais legislação aplicável, toda a cópia, parcial ou total, deste documento, nos casos em que é legalmente admitida, deverá conter ou fazer-se acompanhar por este aviso. 


\section{A. DUARTE GOMES - ANTÓNIO CAETANO JOSÉ KEATING • MIGUEL PINA E CUNHA

\author{
Coordenadores
}

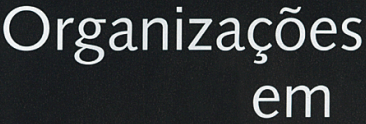

Transição

Contributo da Psicologia do Trabalho

e das Organizaçōes 
(Página deixada propositadamente em branco) 


\section{A. DUARTE GOMES - JOSÉ KEATING ANTÓNIO CAETANO - MIGUEL PINA E CUNHA Coordenadores}

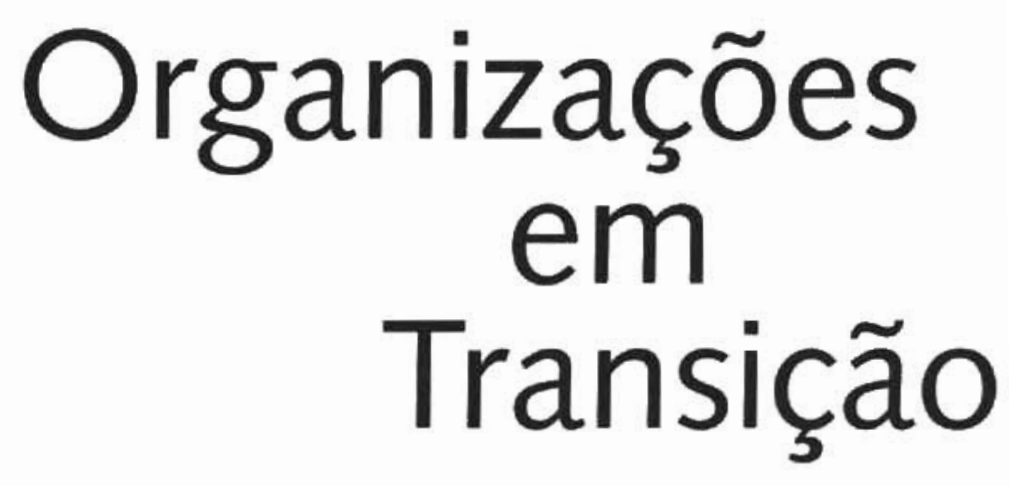

Contributos da Psicologia do Trabalho e das Organizações 


\section{COORDENACÁO EDITORIAL \\ Imprensa da Universidade de Coimbra \\ CONCEPÇÃO GRAFACA \\ António Barros \\ EXECUÇÃO GRAFICA \\ G.C. - Gráfica de Coimbra, Lda. \\ Palheira - Assafarge - Apart. 3068 \\ 3001-453 Coimbra Codex}

ISBN

972-98225-3-0

DEPOSITO LEGAL.

153435/00

(c) JunHo 2000. Imprensa da Universidade de Coimbra 


\section{ASH (AUDITORIA DO SISTEMA HUMANO): MODELOS DE QUALIDADE \\ E AVALIAÇÃO ORGANIZACIONAL}

\section{Santiago D. de Quijano de Arana}

UNIVERSIDADE DE BARCELONA

A globalização da economia, a internacionalização dos mercados, a introdução de novas tecnologias, o poder cada vez maior das associaçōes de consumidores e o seu novo nível de exigência, etc., obrigam as organizaçōes de produção de bens e/ou serviços a funcionar e a agir de maneira cada vez mais eficaz, para sobreviver e desenvolver-se em contextos altamente competitivos.

\section{MODELOS DE QUALIDADE}

A Qualidade, ou mais exactamente a Qualidade Total, concebida como uma filosofia (uma forma de entender a produção, o trabalho, $O$ atendimento ao cliente, os valores da empresa, etc.) e uma tecnologia (entendida em sentido amplo como forma de trabalhar e de gerir), que conduzem a resultados esperados (zero defertos, satisfação do cliente, etc.), converteu-se no leit motiv das organizações, a nivel mundial. Qualquer delas, se pretender sobreviver e crescer, tem de "apanhar o comboio" da Qualidade.

Sendo assim, em diversos locais do mundo (Japão, U.S.A., Europa, Brasil, etc.), aparecem instituições que desenvolvem e promovem actividades para a 
implementação da eficácia e da eficiência das suas organizações, bem como para a concretização da excelência empresarial. Entre as suas actividades conta-se a criação de diferentes Prémios de Qualidade, cujo objectivo é incentivar o esforço para a melhoria da gestão e a obtenção da excelência.

As várias Certificaçōes de Qualidade converteram-se em passaportes e salvo-condutos, necessários para o acesso aos mercados internacionais (e praticamente nacionais), e são uma condição sine qua non de sobrevivência. para o futuro próximo e mesmo imediato.

Tendo em vista avaliar a gestão da qualidade nas empresas, aquelas instituições desenvolveram diversos modelos de avaliação organizacional com uma orientação prática e com o objectivo de melhorar o seu funcionamento. Nestes modelos, de uma forma ou de outra, estabelecem-se critérios de Efectividade Organizacional, além de diversas variáveis que se julga estarem relacionadas com - elou constituintes de - tal efectividade.

São modelos teóricos, formulados apenas de forma verbal. Não são modelos matemáticos, embora as relaçōes expressas entre as suas variáveis (ou dimensões) possam ser matematizadas mediante desenvolvimentos posteriores. Contudo, na sua fase presente, não foram verificados empiricamente através desse tipo de análises matemáticas, embora exista a crença - logicamente fundamentada - de que permitem entender porque é que determinadas organizaçōes funcionam de maneira excelente e de que modo se deve intervir para melhorar as organizações deficientes.

\section{I.I. O MODELO DA EFQM}

Destes modelos, o que está mais próximo de nós é o que foi criado em 199| pela Fundação Europeia para a Gestão da Qualidade (EFQM), em conjunto com a Organização Europeia para a Qualidade (EOQ) e a Comissão

172 Europeia.

O modelo da EFQM contempla uma série de variáveis (ou, antes, dimensões) que são os critérios sobre os quais se baseia a gestão da qualidade nas organizações. Na realidade, este conjunto de variáveis estão agrupadas em duas categorias: as facilitadoras ou Agentes, geradoras da qualidade (Enablers). que se referem ao modo como se conseguem obter os Resultados, e estes (Results), que seriam os diferentes tipos de objectivos prosseguidos pela orga- 
nização, 0 que esta atingiu ou que está prestes a atingir, no momento da avaliação. A representação gráfica do modelo é apresentada na figura 1.

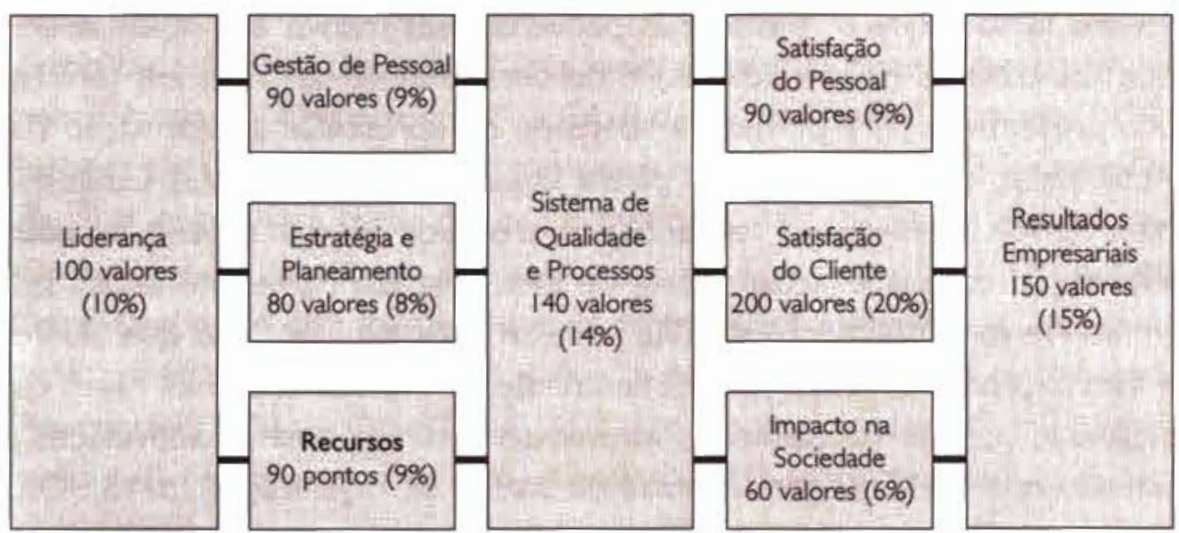

Agentes 500 valones ( $50 \%$ )

Resultados 500 valores ( $50 \%$ )

FGURA I

\section{Modelo da EFQM}

Os Agentes ou Facilitadores são cinco: Liderança, Gestão de Pessoas, Políticas e Estratégias. Recursos e Processos. Os Resultados considerados são quatro: Satisfação do Cliente. Satisfação do Pessoal, Impacto na Sociedade. e Resultados Empresariais. Cada uma das nove dimensões constitui um critério de Qualidade e é avaliado de forma diferente, integrando-se numa escala que pode atingir um total de 1000 valores, sendo 500 atribuídos às cinco dimensões Facilitadoras e 500 às quatro dimensōes referentes a Resultados.

Obviamente, cada uma destas dimensões é definida nominalmente e cada uma delas é dividida em várias sub-dimensões (vários sub-critérios de avaliação), que. por sua vez, são operacionalizadas numa série de indicadores. Uma descrição mais pormenorizada de cada uma delas pode ser consultada na "Application Brochure" para as grandes ou para as médias e pequenas empresas, editada pela EFQM e pela EOQ. 


\subsection{O MÉTODO DE AVALACCĀO DA EFQM}

Nos parágrafos onde se especifica "Como é avaliado", o folheto de aplicação do Prémio de Qualidade para as grandes empresas (que apresenta a mesma filosofia que $\circ$ referente às pequenas e às médias empresas) refere que "os critérios estão cuidadosa e deliberadamente descritos em termos não prescritivos, para permitir a liberdade de apresentar a informação da Auto-avaliação que for relevante para a situação específica" (p. 13). Contudo, oferecem-se orientações e referências concretas, do género "deveria fornecer informação concisa e factual acerca de cada uma das partes em separado" (refere-se às sub-dimensões). Ou, pede-se para explicar "Até que ponto a focalizaçāo foi desenvolvida verticalmente, através de todos os níveis da organização, e horizontalmente, através de todas as áreas e actividades", fazendo referência a distintos níveis de análise da organização (p. 15). Ou, ainda, explicita-se que "Idealmente deveria ser fornecida alguma quantificação que sustente as afirmações" (p. 15), mostrando o desejo de que se confirmem as avaliações qualitativas com dados quantitativos. Importa referir que a focalização incide sobre os métodos utilizados pela organização para abordar cada um dos sub-critérios, sobre a sua utilização e o grau de implantação na organização de cada um desses sub-critérios.

Finalmente, é comunicado a quem apresenta o seu próprio relatório de Auto-Avaliação que os avaliadores esperam encontrar consistência na informação apresentada nos e entre os critérios do Modelo da EFQM. "O Modelo EFQM proporciona um quadro para as organizações efectuarem a sua Auto-Avaliação e promoverem o seu crescimento. A força do Modelo EFQM deriva de um entendimento das relações entre os seus critérios" (p. 16).

Assim sendo, mediante uma aproximação holística e sistémica da organização, com uma metodologia de avaliação de pendor mais qualitativo, com uma determinada concepção de efectividade ou de eficácia organizacional e

174 com um modelo explícito de interligaçōes entre as diversas dimensōes, as três instituições europeias querem e pretendem fornecer um instrumento útil às organizações do continente para o seu crescimento e desenvolvimento, bem como para a prossecução do seu sucesso e da sua excelência. 


\section{MODELOS CIENTIFICOS DE COMPORTAMENTO ORGANIZACIONAL:}

A AVALIAÇÃO ORGANIZACIONAL.

Juntamente com estes modelos de avaliação orientados para a Qualidade, encontram-se os propostos pelos investigadores do comportamento organizacional incluídos numa "área emergente que poderá ser designada como Avaliação Organizacional" (EO) (Lawler, Nadler \& Cammann, 1980). Embora para alguns autores não pareça necessária a ligação da EO a modelos de intervenção - a partir de uma perspectiva mais clássica da avaliação - . são numerosos os autores que sublinham não só o seu objecto de estudo. como também o seu objectivo, que se centra sobre a intervenção, tendo em vista a melhoria das organizações. Nesta linha integram-se os trabalhos de Peiró (1990), Pérez Quintana (1987). Van de Ven \& Ferry (1980). Pérez Velasco \& Fernández Ríos (1985), Quijano (1993) e Fernández-Ríos \& Sánchez (1997).

Em qualquer caso, quer estejam orientados para a intervenção, quer tenham um interesse puramente científico e de desenvolvimento de conhecimentos sobre o comportamento organizacional, todos os autores da $\mathrm{AO}$ insistem na necessidade de dispor de um modelo teórico ou de quadro conceptual de referência, para a procura de informação e para o estabelecimento de relações entre variáveis e/ou dimensōes. Nadler salientou que o investigador dispõe de vários modelos, assim como pode gerar outros, para realizar a avaliação organizacional. Mas seja qual for o modelo ou modelos utilizados, estes devem caracterizar-se por uma série de aspectos que os definem como "científicos". Segundo o autor referido, os modelos devem ser: explícitos, baseados numa teoria, definidos operacionalmente, validados empiricamente e ser generalizáveis.

Só a partir destes modelos é possivel realizar uma $\mathrm{AO}$ que se adeqúe — segundo a definição de Lawler. Nadler \& Camman (1980) - a uma "medida sistemática do funcionamento organizacional, partindo de uma perspectiva de sistema de comportamento, utilizando métodos e procedimentos científicos, caracterizada pela mensuraçāo de um leque de variáveis que abranja o funcionamento de toda a organização e que faça uso de medidas múltiplas ao longo do tempo".

Logicamente, o objectivo desta medida sistemática e científica do funcionamento das organizações orienta-se para a construção de uma teoria geral 
comprovada de comportamento organizacional que permita, a partir de formulações contingentes, probabilísticas, ou de outro teor, explicar como funcionam as organizaçōes e, além disso, para muitos autores, orientar a intervenção e a gestão dirigida a chefias e profissionais, tendo em vista o aperfeiçoamento da sua actuação. Isto quer dizer que, em última análise, a $\mathrm{AO}$ deve trabalhar com modelos matematizáveis, ou seja, com construções teórico-hipotéticas, susceptíveis de matematização, através das quais se represente uma parte da realidade, com o objectivo de proceder ao estudo da mesma e verificar uma teoria (Visauta, 1986).

Contudo, se o nível de explicação pretendido é muito amplo e de carácter geral, os avaliadores costumam basear-se em modelos teóricos "formulados apenas de forma verbal ou de forma matemática genérica, estabelecendo a relação entre variáveis sem especificar o tipo de relação nem a forma das equações que ligam as diferentes variáveis do modelo" (Visauta, 1986). Só quando se entra mais especificamente na descrição ou explicação de alguns aspectos particulares destes modelos é que são propostos outros sub-modelos que, assentes na teoria que os suporta, apresentam maior grau de formalização e descrevem, de forma concreta, as equações ou as relações matemáticas que unem as variáveis.

Este fenómeno de diferenciação entre modelos e sub-modelos, acrescido ao facto de que cada autor utiliza teorias e modelos de comportamento organizacional diversos, conduz, tal como haviam afirmado Van de Ven \& Ferry (1980), à filtragem e à observação do comportamento organizacional segundo diferentes perspectivas, o que levanta a questão das limitações de qualquer avaliação, do mito de uma avaliação completa e final, assim como da impossibilidade de a realizar (Jenkins, 1974; Levy-Leboyer, 1979; Fdez-Ballesteros, 1983; Peiró, 1990). Portanto, qualquer $\mathrm{AO}$ que se realize deve estar consciente dos seus limites, estando condicionada pelos objectivos pretendidos e pelo modelo adoptado pelo avaliador.

É importante referir, além disso, que a AO utiliza modelos de aproxima-

176 ção a diferentes níveis da organização: nível do indivíduo ou do posto de trabalho, nível do grupo elou das unidades e nível sistémico global. Poderá ainda incidir na análise das relações entre os sub-sistemas internos, com outras organizações, ou com o meio em que opera a organização.

Não vamos fazer uma revisão, nem vamos expor aqui a enorme quantidade de modelos existentes e que se reportam a diferentes níveis. Não faria sentido neste trabalho. Uma compilação de muitos deles encontra-se em 
Peiró (1990). Contudo, este autor, inspirando-se em muitos outros (Thompson, 1967; Lawrence e Lorsch, 1967; Galbraith, 1973; Miner, 1982; Pugh \& Pheysey, 1972; Rousseau, 1983; Goodman \& Pennings, 1980, etc.), propõe um esquema que estabelece "os elementos relevantes para a elaboração de modelos abrangentes da organização e do comportamento organizacional, considerado a diferentes níveis". De acordo com uma série de pressupostos básicos sobre as organizações, entendidas como sistemas abertos, comportando múltiplos níveis (individual, grupal, organizacional), imersos num contexto, susceptiveis de "design", por se tratar de fenómenos artificiais, o referido autor propöe quatro elementos que deveriam ser contemplados em qualquer modelo de comportamento organizacional: o Contexto (meio e inputs). o "Desenho" (estrutura, processos de transformação), os Resultados (desempenho, produtos) e a Retro-alimentação ou feedback.

\section{ASH (AUDITORIA DO SISTEMA HUMANO) E MODELO DE AO QUE LHE DÁ SENTIDO}

\subsection{AsH}

ASH são as iniciais de Auditoria do Sistema Humano. Trata-se do conjunto de instrumentos elaborados no Departamento de Psicologia da Universidade de Barcelona e na Fundação Bosch i Gimpera (daquela mesma Universidade), como resposta a uma solicitação da União Patronal Metalúrgica (UPM) da Catalunha à referida Fundação. A UPM solicitou à Fundação Bosch i Gimpera a criação de instrumentos para o diagnóstico ou a avaliação da Gestão Estratégica de Recursos Humanos nas pequenas e médias empresas. O ASH surgiu, pois, desde o seu início, com uma clara intenção de Avaliação para a Intervenção orientada para a Efectividade Organizacional.

$\mathrm{O}$ ASH foi elaborado, não como um conjunto de instrumentos justapostos para avaliar diferentes aspectos da gestão de RRHH. nas empresas, mas como uma unidade que é composta de partes interligadas que correspondem a um Modelo ou Sistema de Gestão de RR.HH., que, por sua vez, se compõe de diferentes sub-sistemas, sendo ele próprio um sub-sistema do maior e mais complexo Sistema Aberto que é a Organização. Portanto, a sua apresentação exige a explicitação do Modelo de Gestão de RR.HH. que dá sentido e coesão às suas partes, assim como exige a explicitação do Modelo de Comportamento Organizacional mais amplo em que se integra e que o suporta. 


\subsection{O MODELO DE COMPORTAMENTO ORGANIZACIONAL QUE APOIA O ASH}

O modelo que aqui vamos apresentar é um modelo teórico, expresso de forma verbal, de carácter geral, e as relações entre as suas dimensões e variáveis não serão descritas mediante equações matemáticas comprovadas. Isto não impede que possamos avançar na descrição ou explicação mais pormenorizada de alguns dos seus aspectos, de maneira a especificar o grau de concretização e de formalização daquelas áreas mediante a apresentação de sub-modelos cujas variáveis relacionadas possam, finalmente, ser expressas - a níveis mais concretos e precisos - em equações estruturais ou outras relações matemáticas definidas. Nesse sentido, procederemos por partes e, à semelhança do que ocorre num programa windows, iremos vendo o conjunto dos elementos disponíveis e/ou relacionados e, progressivamente, iremos abrindo diferentes janelas, ampliando, assim, a informação.

Importa, ainda, sublinhar que o nosso modelo de comportamento organizacional se centra na perspectiva do comportamento humano nas organizações. Portanto, não é um modelo completo e exaustivo de tudo quanto acontece numa organização. $O$ comportamento económico da organização, por exemplo, ou as transformaçōes que sofrem as matérias-primas submetidas a processos produtivos, não serão abordados aqui. Se a economia, a tecnologia utilizada, ou a estrutura dos postos de trabalho, entre outras, são tratadas neste modelo, apenas o são na medida em que incidem sobre o comportamento das pessoas, ou na medida em que estas, quando têm poder de decisão, escolhem e integram determinadas estruturas e processos, relativamente a estas questões, tendo em vista alcançar os objectivos que se propõem.

Dito isto, o modelo que suporta o ASH é o seguinte: 


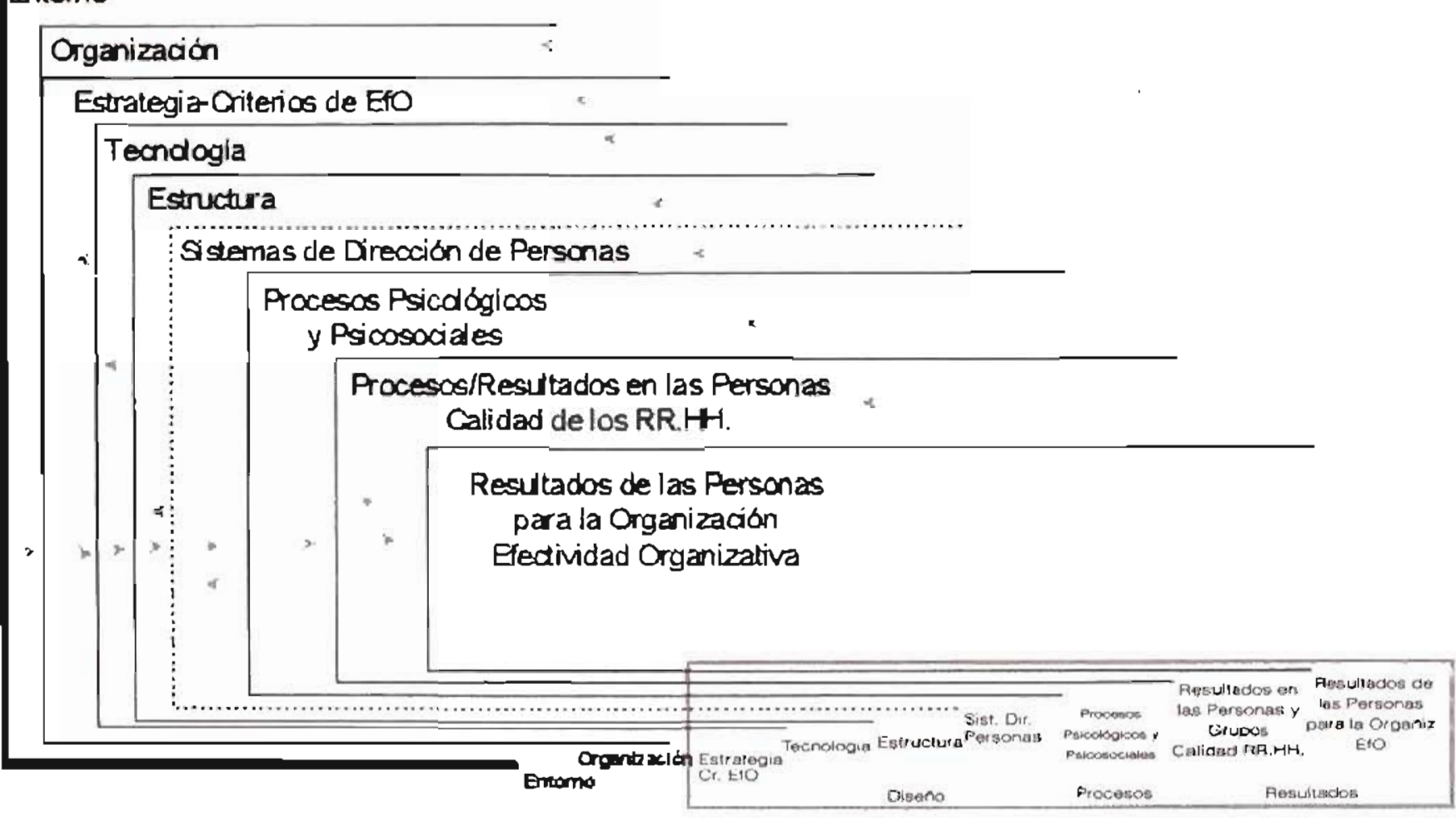

FIGURA ZA 
RESULTAOOS

PSIC $Y$

CALIDAD

EFECTIVIDAD

ENTTORNO ESTRATEGIA

DISEÑO

PSICOSOC

RR HIH

ORGANIZATIVA

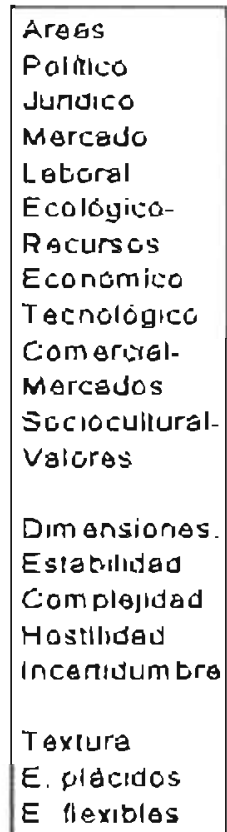

Visión
Misian
(Velores)
Objetiyas
Generales
OEjetivas
Especificas
Plengs de
Acción

SISTEMAS Y TECNOESTRUC

\section{GESTIOH. Y}

OES RR HH.

-Selección

-Formación

-Rernbucion

-Eval Ranu

- Com intema

- Iuent Pal. s'

Planes Carr

-Preven. Riesg.

'S Salud

-Planif RR $\mathrm{HH}$

Iniggracion

RELACIONES

LAEOR ALES

- Asesoria

jurióca-lataral

- Negociación

calecuya

ADMCON

PER SONAL
T ESTRUC

C Psicesonales ORGANIL

$E$-plenss

-piramidalas

$c$-an reu

-metriciales

is $-a t c$

0

L

0

Diseñode

3 puesios,

iareas ' $y$

1 procesos

$\cup$ Liverazgo

Cilima

Organizaliyo

L Conflicto

$T$ Participación

$U$ Toma

$R$ Decisiones

$A$

$\Rightarrow C A M E I O=$

A

Clima Grupal

Grupalıdad

Psicologicos

conflicto rol

Ambigued rol

Sobrecarge Irab

Equidad

Autoeficacia
ECONOMICOS

Financieras

Comerciales

Prouucliyos

SOCIALES

Extemos

Intemos

AMEIENAT ALES

conc resulls
Func Equipes

F

Produciruidad

Grupal

l dentificecion b'

Comuromiso

Molivesién

Competencias

Estres. Burnaut

Salistacción
Resullados

Desamparios

Accidentat

Aosentismo

Rotación 


\subsubsection{O MEIO: TAXONOMIA, DIMENSŌES E TEXTURA}

primeiro pressuposto de que partimos é o de que todas as organizações são um sistema aberto, em relação constante com um meio multifacetado e em mudança, com o qual trocam inputs e outputs. As organizaçōes são influenciadas por esse meio envolvente e, de certa forma, moldam-no e contribuem para a sua construção. Ou seja, as organizações não só se adaptam ao meio envolvente e reagem perante o mesmo, como também agem sobre ele e, de certo modo, contribuem para o moldar.

O conceito de Meio ou Envolvente implica, sob uma aparente simplicidade, uma abordagem extremamente complexa. Podemos e devemos considerar na Envolvente diferentes aspectos: a taxonomia de áreas (1), as suas dimensōes (2) e a sua textura (3).

Por taxonomia de áreas do meio envolvente entendemos a classificação do mesmo com base em temáticas ou conteúdos particulares que afectam de modo diferente as organizações, induzindo nelas diferentes configurações no que toca a estratégia, tecnologia, estrutura, processos, sistemas, comportamento geral e hipóteses de efectividade. Estas áreas são: o meio económico, o tecnológico, o político, o jurídico, o ecológico ou propiciador de recursos naturais, o mercado de trabalho, o comercial ou mercado de produtos/serviços e o sócio-cultural ou valores sociais dominantes. Na realidade, embora sejam abordadas como diferentes ou como independentes entre si, todas estas áreas estão interligadas, mas considerá-las separadamente constitui uma estratégia que tem em conta a nossa capacidade limitada e visa facilitar a sua compreensão.

Assim, por exemplo, o meio económico influencia o comportamento organizacional de diferentes formas e, entre outras, as seguintes dimensōes: - poder de compra dos potenciais consumidores de produtos ou serviços, atendendo aos seus níveis de rendimento. a disponibilidade de crédito e o preço do dinheiro, os tipos de mudança e as etapas do ciclo económico.

Outros indicadores de outras áreas do meio são, de forma sumária e obviamente não exaustiva, os seguintes: a tecnologia disponível no mercado, as regulações governamentais, a legislação laboral, as decisões políticas relativas ao controlo do déficit público e à inflação (político-jurídico), a disponibilidade de recursos naturais e de matérias-primas, a obrigatoriedade de reciclar resíduos, a pressão social face à poluição ambiental (ecológico, jurídico-legal, 
sócio-cultural, etc.), a disponibilidade de recursos humanos preparados para a utilização de novas tecnologias (mercado de trabalho), os valores sociais dominantes (sócio-cultural), o posicionamento competitivo das empresas do mesmo sector, os nichos de mercado existentes (mercado, comercial), etc., etc.

Todas estas áreas e os seus indicadores não apresentam a mesma relevância para as organizações. De facto, um dos problemas que estas devem resolver, ao avaliar o seu meio envolvente, é o da escolha acertada de quais as áreas que as afectam de forma importante, quer seja a nivel global, quer seja a nivel de algumas partes do sistema.

Para além das áreas do meio, sempre dinâmicas, interligadas e em constante mudança, é preciso avaliar as suas dimensões. Por dimensões entendemos as características comuns a diferentes áreas ou a qualquer taxonomiá considerada que se revelam imprescindíveis quando se pretende realizar um diagnóstico ou uma avaliação do meio. Servem "para determinar situaçōes contingentes entre 0 meio e as características organizacionais" (Husenman, 1985). Na sequência de Schoderbeck et al. (1980), Mintzberg (1979) e Duncan (1972), Husenman (1985) propōe quatro dimensōes: estabilidade, complexidade, hostilidade e percepção da incerteza. Obviamente, cada uma delas, por sua vez, inclui diversos indicadores. Por exemplo, a estabilidade inclui a frequência da mudança, a variabilidade ou a diferença entre distintas mudanças, assim como a regularidade ou irregularidade do padrão de mudança. Para uma análise mais detalhada, recomenda-se a consulta dos autores referidos.

Finalmente, importa estabelecer tipologias do meio ou perfis de situaçōes que, atendendo às dimensões analisadas, se revelem úteis para avaliar a adequação do comportamento organizacional ao seu meio envolvente. Apoiando-se no conceito introduzido por Emery \& Trist (1965) e também utilizado por Ansoff (1976a, 1976b, 1977). Husenman (1985) descreve o conceito de textura do meio como um estado global do comportamento do mesmo e que resulta do carácter e da combinação das suas dimensões. Finalmente, propōe

182 quatro tipos puros de textura ou de comportamento do meio ambiente: calmos, flexíveis, em ebulição e turbulentos. Convidamos novamente o leitor a aprofundar o tema, consultando os autores citados. 


\subsubsection{A ORGANIZAÇĀO}

Imersa no seu meio, reagindo perante ele, adaptando-se e, simultaneamente, configurando-o de forma proactiva, a organização constrói-se a si própria e age. $E$, mesmo quando se comporta como um sistema complexo de partes e de elementos interligados, para podermos realizar uma aproximação conceptual a esse sistema, teremos que analiticamente distinguir várias dimensões: a Estratégia; o "Design: Tecnologias, Estrutura e Sistemas; os Processos Psicológicos e Psico-sociais; bem como a Efectividade Organizacional, que inclui duas dimensões: Resultados nas pessoas ou Qualidade dos RR.HH, e Resultados para a Organização e a Sociedade: económicos e financeiros, produtivos e comerciais; ecológicos; sociais.

\subsubsection{A ESTRATEGIA}

Por planeamento estratégico entendemos a resposta dada pela organizaçāo ao meio, depois de o analisar (em termos de ameaças e oportunidades) e de tomar consciência dos seus próprios recursos para o enfrentar (pontos fortes e fracos). Normalmente, é elaborado pela Direcção, com a participação de todas as pessoas que detêm poder na organização. Obviamente, o número e o tipo de pessoas incluídas neste processo depende da cultura mais ou menos participativa da organização.

Thompson \& Strickland (1994) definem tal planeamento estratégico como os movimentos e as focalizações que a gestão concebe para conseguir que a organizaçāo obtenha excelentes resultados. Comporta cinco componentes, relacionados entre si: 1) Desenvolver um conceito do negócio e ter uma visão em direcção à qual orientar a organização... estabelecendo uma missão. 2) Transformar a missão em objectivos específicos e resultados. 3) Elaborar uma estratégia que permita atingir o resultado planeado. 4) Implementar e pôr em prática a estratégia seleccionada, de maneira eficiente e eficaz. 5) Avaliar o resultado, rever a situação e operar ajustamentos correctivos na missāo, nos objectivos, na estratégia ou na sua implementação, tendo em conta a experiência real, a mudança das condições, as ideias e as novas oportunidades (pp. 2 e 3).

A estratégia da empresa define, entre outras coisas, o domínio ou sector de actividade em que a mesma irá operar, as linhas de negócio em que irá 
concentrar os seus recursos, a tecnologia que irá ser incorporada nos seus processos produtivos, a estrutura e os sistemas de que se dotará para conseguir atingir os seus objectivos e - o que é mais importante - os critérios de eficácia ou de efectividade organizacional que irá utilizar como referentes para avaliar o seu sucesso. Este conjunto de elementos interligados entre si, de forma sistémica, constituem uma forma de se ver a si mesma no futuro imediato, operando de uma determinada maneira e atingindo objectivos específicos. É a isto que chamamos visão da empresa. $O$ sentido ou significado dado a esta forma de se ver no futuro (imediato, a médio ou a longo prazo). o porquê da mesma e a sua justificação, assim como as suas repercussões na sociedade em que se insere, constituem a missão da empresa.

Em qualquer caso, visão e missão surgem de e incorporam determinados valores, assim como objectivos gerais e objectivos específicos, que, finalmente, e por um processo de repercussão em cascata, se traduzem em objectivos a atingir pelas divisōes, pelos departamentos e pelos indivíduos, nos seus postos de trabalho. Obviamente, este processo, descrito de forma compacta e tão racional, não deixa de ser, em muitos casos, algo de teórico, emergindo, na prática, algo truncado ou modificado por múltiplas forças. As análises do meio envolvente podem, ou não, ser feitas; podem ser bem ou mal feitas; assim como a estratégia pode ser pensada em todas as suas dimensões, ou não; pode ser formulada, ou não, por escrito; pode, ou não, estar correcta. De qualquer forma, pensada ou não, completa ou parcial, escrita ou pensada, partilhada por todos os membros ou pensada apenas pela direcção, a organização dá uma resposta ao seu mercado e a uma envolvente, multifacetada, como referimos.

A determinação dos elementos presentes na sua resposta, em particular o referente aos critérios de eficácia, é influenciada pelos valores da organização, os quais remetem para a sua cultura. Esta constitui um dos grandes processos psico-sociais que ocorrem nas organizações.

I84 Por isso, no nosso modelo dos processos psicológicos e, em especial, dos psico-sociais surgem setas que representam a influência que estes exercem sobre as restantes dimensões do funcionamento organizacional. Os valores da cultura do grupo dominante influenciam a escolha da estratégia. Mas a influência é recíproca, porque, como facilmente se entende, também a direcção e as pessoas que detêm poder formulam, por vezes, estratégias que incluem novos valores, modificações de alguns que tradicionalmente haviam sido tidos em 
conta na organização, ou significam a supressão de outros que, até então, se haviam revelado úteis para o seu sucesso.

\subsubsection{O "DESIGN":TECNOLOGIA E ESTRUTURA}

Uma das decisões inerentes à Estratégia da empresa refere-se à Tecnologia que a organização adoptará, de entre as que o meio disponibiliza, para concretizar os seus processos de produção de bens ou de serviços, de atendimento aos clientes, etc., para atingir os seus objectivos.

Se a tecnologia de produção adoptada pela organização é de série, de processo, ou unitária, tal terá repercussões importantes sobre a estrutura organizacional, no que concerne à eficácia (Woodward, 1958, 1965). Também influenciarão outros indicadores, tais como: a tecnologia adoptada nos processos produtivos é analisável ou não analisável, familiar ou não familiar.Tal permitirá configurar quatro tipos de organizações: rotineira, não rotineira, engenharia e serviços. Estas diferentes configuraçōes terão claras repercussōes sobre a estrutura dos postos de trabalho, sobre as comunicações, assim como sobre as relações entre chefias, subordinados e colegas, para referir apenas algumas (Perrow, 1970).

Mas será, sobretudo, a incorporação de novas tecnologias que influenciará de forma relevante o comportamento organizacional. Em particular, a Microelectrónica, a Informática, as Telecomunicações e a Automatização geraram aquilo a que Halton chamou a segunda revolução industrial e estão a influenciar e modificar profundamente não só os postos de trabalho, os papéis, as carreiras profissionais, as relações inter-pessoais, o trabalho em equipa, como também outros aspectos, como a gestão de RR.HH., a distribuição comercial, etc. (cfr. Peiró, 1990; Prieto, 1987; Munduate, 1985, 1990; Peiró \& Prieto, 1989; Kavanagh et al., 1990; Aragonés, 1997; Ferreiro \& Tanco, 1997).

Logicamente, as decisōes tomadas a resperto da tecnologia, assim como outras referentes à tomada de decisões e à distribuição do poder, a necessidade de formar equipas de trabalho e de facilitar a troca de informação para a realização de tarefas, ou de aproximar a empresa do cliente, etc., conduzirão à adopção de diferentes formas de Estrutura: mais ou menos achatada, matricial, em rede, por grupos de negócio descentralizados, de menor dimensão, etc. 


\subsubsection{O "DESIGN": OS SISTEMAS DE GESTÃO DE PESSOAS}

Se a obtenção de recursos financeiros, a adopção de tecnologias de ponta, ou o estabelecimento de uma adequada estrutura organizacional, são factores-chave para o sucesso e para a consecução de objectivos estratégicos, em qualquer empresa, não é menos verdade que um tal sucesso só é possivel se estiver presente um quarto factor, que, em muitos dos casos, é tão importante como os primeiros: a preparação, integração e empenhamento dos seus Recursos Humanos.

$E$ ainda que possamos admitir que a percentagem de sucesso empresarial explicado pela Qualidade dos seus Recursos Humanos é variável nas organizaçōes e que o mesmo pode ser função das tecnologias que utilizam, do sector produtivo em que operam, ou de outras variáveis contingentes, é de esperar que, em todas elas, um determinado nível de competências e de comprometimento dos seus empregados, assim como o seu esforço para fazer o trabalho bem feito, seja considerado indispensável.

Peters \& Waterman em 1982, mais do que demonstrar, chamaram a atençāo para a enorme importância que a Cultura Organizacional tinha na excelência das melhores e mais competitivas empresas norte-americanas. E também Misa \& Stein (1983) salientaram ser a Direç̧ão de Recursos Humanos a principal força estratégica, desenvolvida pelas 500 melhores empresas Fortuna para conseguir o seu sucesso. Para além da dificuldade de demonstrar realmente, de forma científica, a variação de sucesso das organizações que é explicada pelos seus Recursos Humanos, cremos que este é um factor-chave que é preciso analisar em pormenor.

De certa forma, poderíamos considerar os Sistemas de Gestão de Pessoas das organizações como participantes da sua estrutura, visto estabelecerem formas reguladas de gerir e de tratar tudo o que se refere às pessoas que integram a organização e nela trabalham. À semelhança de uma estru-

186 tura, também os Sistemas de Gestão de Pessoas são influenciados (ou deveriam ser influenciados) pela Estratégia definida, em conexão com a Visão da Empresa e com os Valores que a inspiram. E também pela Tecnologia. Contudo, na designação Gestão de Pessoal muitas e diversas coisas foram incluídas e, na nossa opinião, convém esclarecê-las.

Embora alguns autores (Yoder \& Heneman, 1977; French, 1983; Deguy, 1989; Dessler, 1988) os considerem praticamente idênticos ou sinónimos 
(e muitos empresários e dirigentes também), pensamos que existem três subsistemas diferenciados no Sistema de Gestão de Pessoas. Os três foram sendo desenvolvidos progressiva e sucessivamente, de acordo com as necessidades que foram surgindo, ao longo do tempo, no que concerne à relação pessoas-organização, assim como foram condicionados pelas diferentes concepções que a organização tem tido dos trabalhadores. Os três sub-sistemas são: o da Administração de Pessoal, o das Relações Laborais, e o da Gestão e Desenvolvimento de Recursos Humanos, a que presentemente e nas suas formas mais avançadas, chamamos Gestão Estratégica de Recursos Humanos. A posição aqui por nós defendida insere-se na linha de propostas apresentas por Besseyre des Horts (1988a, 1988b), Singer (1990), Cascio (1991), Byars \& Rue (1991) e Gómez-Mejía, Balkin \& Cardy (1995), entre outros.

As diferentes funçōes que, relativamente às pessoas, cumprem os três sub-sistemas referidos estão relacionadas com a evolução histórica das organizações, do trabalho, e do contexto jurídico e social em que aconteceram. Na realidade. podenámos falar de quatro funçōes diferentes: a função de controlo (1), a função administrativa (2), a função reguladora (3) e a função de motivação, desenvolvimento e contrato psicológico (4).

A função de controlo, relacionada com a informação sobre as pessoas e a influência sobre o seu comportamento, esteve presente desde o início da revolução industrial e da existência das organizações industriais, ou mesmo, para certos autores (como Amaro, 1981), desde a própria origem da sociedade. Certamente a maneira de entender este controlo foi assumindo diversas formas conceptuais e práticas na vida organizacional. Desde ser entendido como domínio despótico sobre o pessoal, baseado na coacção ou na força física ou psicológica, passando pelo controlo entendido como consciência e adopção de processos e verificação de resultados atingidos, relativamente a pessoas e à organização, realizado por chefes no exercício da sua responsabilidade para detectar e rectificar falhas e erros, até ser entendido como auto-controlo, na medida em que a organização influencia o comportamento dos seus empregados mediante a interiorização que eles próprios fazem de valores, de padrões de comportamento e de metas, sem que para isso seja necessário o exercício externo da força ou do poder de coacção.

Outra função da Gestão das Pessoas foi a função administrativa, que tem vindo a ser realizada por muitos "chefes de pessoal" e que esteve centrada na elaboração de mapas de vencimentos, realização de contratos de trabalho, 
organização das férias do pessoal, controlo de baixas, etc. Esses "chefes" orientavam a sua acção por normativos e estavam preocupados com o cumprimento das normas internas da organização e com o seu ajustamento à legislação em vigor. Poderia comparar-se à função de compras e de aprovisionamento de materiais necessários aos processos produtivos. Tal como estes não podem ser realizados sem matérias-primas, sem máquinas, ou sem peças de substituição, indispensáveis à manutenção dessas máquinas, também as pessoas, ou mão-de-obra, eram indispensáveis à sua realização. A função de pessoal tinha como objectivo assegurar o aprovisionamento de mão-de-obra, embora a sua responsabilidade não implicasse a procura da mais eficiente, nem a sua formação ou desenvolvimento, com vista a obter uma maior efectividade organizacional, em consonância com os objectivos estratégicos da empresa. Da mesma maneira que não exigia potenciar a sua qualidade de vida profissional ou a sua satisfação no trabalho.

Com o progresso da legislação laboral e a conquista dos direitos dos trabalhadores, pela acção dos movimentos operários e sindicais, a função administrativa foi sendo progressivamente superada por uma outra, mais complexa e mais difícil, centrada na regulação das relações entre sindicatos e direcção, ou relações sindicais e patronais, bem como na negociação e resolução de conflitos surgidos entre actores organizacionais, no quadro da legislação laboral em vigor. É a função reguladora das relações industriais, ou relações laborais, e o seu paradigma fundamental é o conflito.

As relações laborais continuam, hoje, a existir, mas a sua abordagem é redutora ou limitada e incapaz de suscitar a motivação dos empregados, a sua identificação e o seu comprometimento com a organização, a sua implicação no trabalho, o desenvolvimento de atitudes positivas e o seu adequado nível de competências para responder às exigências do meio tecnológico, económico, de mercado, etc., em mudança vertiginosa.

Face a estas limitações, finalmente, como uma necessidade premente, 188 surgiu a função de desenvolvimento, motivação e contrato psicológico. Esta é a abordagem da Gestão e Desenvolvimento dos Recursos Humanos e, na sua versão mais avançada, da Gestão Estratégica dos mesmos. Os profissionais que a realizam são, cada vez em maior número, universitários provenientes das Ciências Sociais e/ou da área do comportamento humano (sociólogos, psicólogos, antropólogos, pedagogos, etc.).

O desenvolvimento progressivo de cada um destes sub-sistemas não só 
não anulou ou tornou desnecessário o anterior, como o integrou, enriquecendo e ampliando os pressupostos sobre os quais agia e os objectivos que pretendia alcançar. As Relaçōes Laborais não anularam a Administração de Pessoal, que continua a ser necessária e que hoje é realizada em todas as empresas. A Gestão Estratégica de RR.HH. também não anulou, nem tornou desnecessárias, as Relações Laborais, que continuam a estar presentes e vigoram em todas as organizações. Simplesmente, ampliou e enriqueceu as hipóteses dos anteriores sub-sistemas de Gestão de pessoas, melhorando a interaç̧ão da organização com os seus membros, tornando mais efectiva a sua contribuição para a consecução dos objectivos estratégicos e para a Efectividade Organizacional. De facto, muitos Departamentos de Recursos Humanos cobrem as quatro funções descritas: de controlo, administrativa, reguladora e motivadora ou integradora (InformAedipe, 1998). Nas organizaçōes de maiores dimensões, estas funções estão, por vezes, repartidas entre vários Departamentos, mas, mesmo assim, podem ser globalmente integradas por um outro Departamento mais abrangente de Gestão de Pessoas, podendo este receber este ou outro nome. Em sintonia com o exposto, salientam-se autores como Amaro (1981). French (1983), Dyer \& Holder (1988), Besseyre des Horts (1988), Cascio (1989), Kavanagh et al. (1990), Singer (1990), Fernández Caveda (1990), Dulebohm, Ferris \& Stodd (1995).

\subsection{O Sistema de Gestão Estratégica de Recursos Humanos}

Iremos, agora, centrar-nos sobre o Sistema de Gestão Estratégica de Recursos Humanos e sobre a sua função específica de integração e de motivação das pessoas. A primeira coisa que queremos sublinhar é que se trata de um Sistema e, portanto, de um conjunto de elementos interligados, com vista à produção de outputs, de tal forma que qualquer modificação que se produza num deles irá afectar, quer se queira ou não, todos os outros, de uma ou de outra forma. Mais: a sua potência geradora de outputs de alta qualidade estará em grande medida relacionada com a integração e a interligação dos elementos que o constituem.

Por outro lado, o Sistema de Gestão Estratégica de Recursos Humanos pode ser considerado como um Sub-sistema do Sistema aberto maior que é a Organização, interagindo com outros, como a Estrutura, a Tecnologia, 
a Estratégia, etc. Por isso, sub-sistema ou sistema sāo formas de nos referirmos quer aos elementos de outros sistemas maiores, quer aos sistemas relativamente maiores, que, por sua vez, são formados por conjuntos de elementos menores que interagem e processam inputs, de maneira a gerar outputs. Neste ponto, a nossa posição tem em linha de conta as contribuições de Chiavenato (1981), French (1983), Fitz-Enz (1984), assim como as de Dyer \& Holder (1988) e Singer (1990), entre outros.

Em sentido amplo, os elementos do Sistema de Gestão de RR.HH. podem ser classificados em cinco grandes categorias: as Técnicas de apoio (1); os Sistemas de Gestão e de Desenvolvimento dos RR.HH. (2); os Processos Psicológicos e Psico-sociais geradores que produzem (3); os Processos/Resultados nas Pessoas ou Qualidade dos Recursos Humanos (4); e os Resultados das Pessoas para a Organização, os quais contribuem para os Resultados dos Grupos, com vista à Efectividade Organizacional (5).

Num sentido mais restrito, podem ser considerados apenas os dois primeiros, que são os tradicionalmente contemplados na Gestão de RR.HH. e os mais próximos da estrutura organizacional:Técnicas de apoio e Sistemas de Gestão.

De facto, as categorias três, quatro e cinco - Processos psicológicos e psico-sociais (3), Qualidade dos RR.HH. (4) e Efectividade Organizacional (5) - serão aqui desenvolvidos como elementos independentes, diferenciados do Sistema Estratégico de Gestão de RRHH., neste modelo de comportamento organizacional que estamos a descrever.

\subsection{As Técnicas de apoio}

190

Por Técnicas de apoio (suporte) entendemos uma série de tecnologias que preparam e criam as bases para estruturar e desenvolver os sistemas de gestão. A mais básica, prévia a qualquer um dos sistemas de RR.HH., é a análise e descrição de funções ou postos de trabalho, que permite elaborar o Inventário dos postos de trabalho da organização; que servirá de apoio à definição de Perfis para o Recrutamento e Selecção; à Qualificação de funçōes para efeitos de Retribuição; ao Redesenho (redesign) dos postos de trabalho 
que compõem a Estrutura Organizacional; à identificação de competências e de atitudes (perfis) que é preciso desenvolver através da Formação (necessidades), com vista ao Desenvolvimento de Carreiras; ao estabelecimento de Critérios para a Avaliação de Desempenho.

Apesar de alguns autores terem falado do "fim dos postos de trabalho", devido à vertiginosa rapidez com que estes actualmente se modificam, isto não passa de um jogo de palavras que procura efeitos mais ou menos sensacionalistas, já que há sempre um conjunto de tarefas ligadas e integradas num processo, com vista à realização da tarefa fundamental. Este conjunto de tarefas - mais estáveis ou mais mutáveis, mais independentes ou mais interdependentes - que as pessoas deverão realizar no seu trabalho (de forma mais individual ou mais grupal), para atingir os objectivos organizacionais, é o que continuaremos a chamar postos de trabalho. Estes serão, provavelmente, mais flexíveis e mutáveis no futuro, assim como mais interdependentes, mas continuarão a existir. $E$ a sua descrição (concebida como a identificação de deveres, de responsabilidades e de condições de trabalho, assim como a descrição das tarefas a realizar) e a sua análise (concebida como as dimensões ou as características destas tarefas e como as aptidões, os conhecimentos e as competências requeridas) continuarão a ser necessárias para estabelecer os Sistemas de Gestão. Por exemplo, o "design" dos postos de trabalho poderá ser realizado numa perspectiva mais individualista ou mais grupal (Hackman 1983. 1987), mas a sua execução continuará a ser necessária.

Outras técnicas de apoio, baseadas na Análise e descrição de funções são, como já referimos, a Qualificação de funções, a Identificação de perfis (incluída como uma parte da análise de funções), o Redesenho e o Enriquecimento de funçōes (ou postos de trabalho), ou o seu Inventário.

\subsection{Os Sistemas de Gestão de RR.HH.}

As técnicas de apoio permitem estabelecer os propriamente chamados Sistemas de Gestão de RR.HH. São eles: o de Selecção, o de Formação, o de Retribuições e Recompensas, o de Avaliação de Desempenho, o de Identificação de Potenciais e Planos de Carreira, o de Comunicação, o de Planeamento (ou gestão previsional) de RR.HH. e o de Segurança e Saúde no trabalho. Na medida em que todos eles são sub-sistemas de um sistema maior, encontram- 
-se interligados, ou é assim que deveriam encontrar-se, no sentido de tornar mais forte e saudável esse sistema. Se se encontrarem desintegrados ou desagregados, de forma que não exista relação entre eles, os outputs de uns não servem de inputs para os outros, o sistema global de RR.HH. perde força e, no pior dos casos, pode terminar numa justaposição de acções contrárias ou contraditórias, que não só não trazem valor acrescentado à gestão da organização com vista à obtenção da Efectividade Organizacional, como podem mesmo vir a prejudicá-la. Além disso, a sua integração não só tem a ver com a relação que mantêm entre si, como também tem que ver com as relações com os outros componentes do sistema organizacional que estamos a descrever. Deste modo, os sistemas de Gestão de RR.HH. deverão estar em consonância com a Estratégia da Empresa, estar orientados para o alcance dos objectivos por ela estabelecidos e estar relacionados com os valores e a cultura da organização.

O Sistema de Avaliação de Desempenho, por exemplo, quando está bem integrado no Sistema global de Gestão de RR.HH., dá outputs que são bons inputs para o Sistema de Remuneração e de recompensas (estabelecimento de remuneração variável), para o de Formação (levantamento das necessidades e avaliação de acções de formação), para o de Identificação de Potenciais e Planos de carreira (identificação de potenciais candidatos) e para o de Selecção (critério de sucesso da selecção). Também os Sistemas de Formação e de Comunicação devem oferecer suporte ao de Segurança e Saúde no trabalho. Mais: todos estes sistemas não devem apenas estar ligados entre si. devem, também, como já foi aqui afirmado, estar ligados à cultura e aos objectivos estratégicos da organização. Se, por exemplo, uma organização quiser potenciar uma cultura de Qualidade Total não poderá continuar a pagar os empregados segundo critérios de antiguidade, consoante a quantidade de produto produzido, ou sem atender aos desempenhos como uma forma de realizar o trabalho com um determinado estilo que expresse os novos valores

192 organizacionais a potenciar. Deve igualmente incorporar no Sistema de Avaliação de Desempenho critérios de desempenho relacionados com a Qualidade Total, assim como apoiar os novos valores e os comportamentos desejados através dos sistemas de Formação e de Comunicação. Uma representação gráfica do Sistema de Gestão e Desenvolvimento de RR.HH., entendido no seu sentido mais amplo, encontra-se na figura 3. 
Diagrama del Sistema de Gestión Integrada de Recursos Humanos

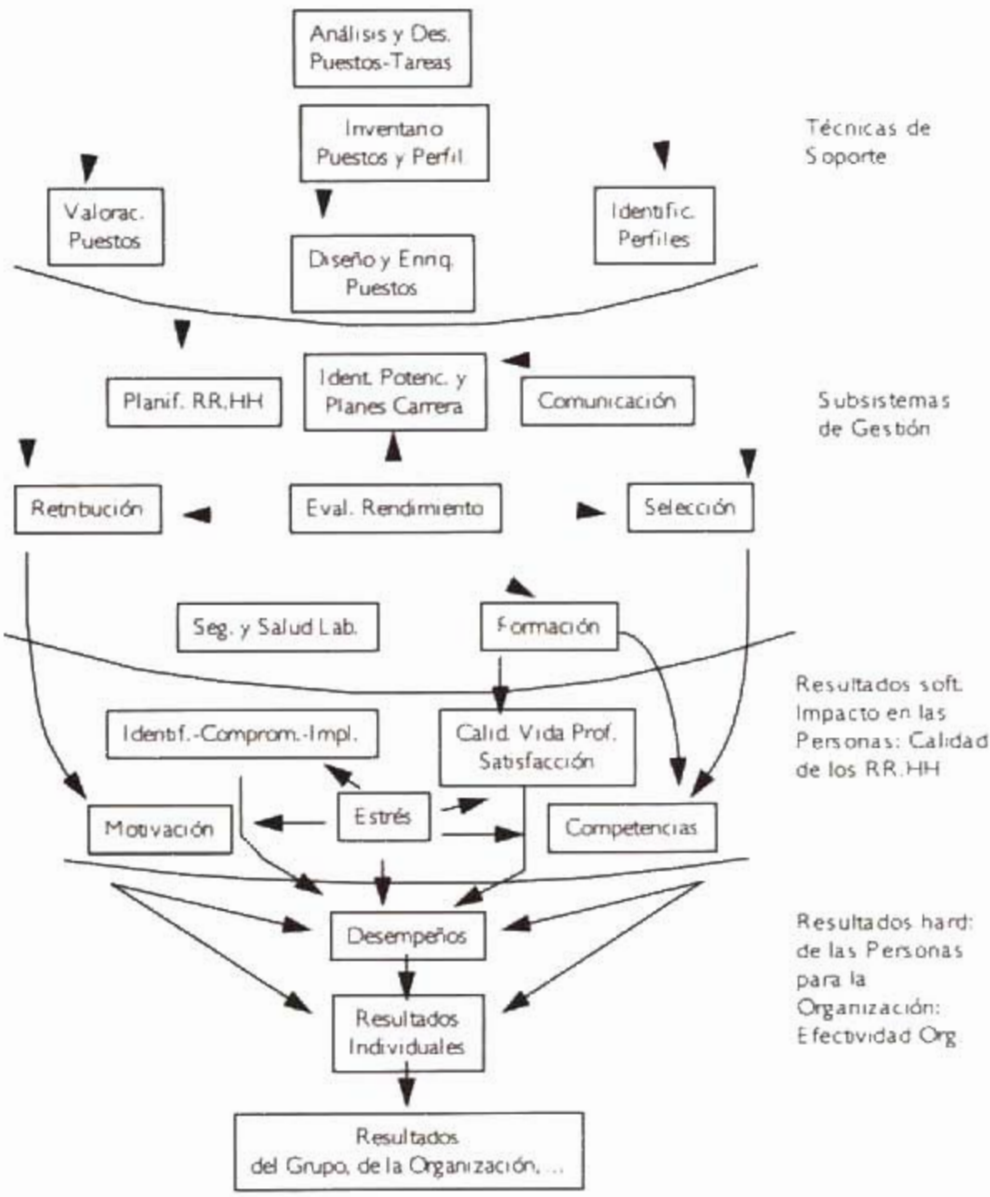

conectores. Ios outputs de un sistema son inputs para otros sisternas

relaciones de influencia

Solo se presentan algunos conectores y relaciones de influencia

FIGURA 3

\subsubsection{OS PROCESSOS PSICOLOGICOS E PSICO-SOCIAIS}

$\mathrm{Na}$ apresentação do ponto relativo ao Sistema de Gestão de RR.HH., entendido em sentido amplo, fizemos referência aos seus objectivos, isto é, aos resultados pretendidos pela Gestão, quer seja de forma imediata (relativamente às pessoas), quer seja em última instância (relativamente à organiza- 
ção). Rotulámo-los como processos/resultados nas pessoas ou Qualidade dos RR.HH. e como processos/resultados das pessoas para a organização ou Efectividade Organizacional. É claro que falar de processos e de resultados é sempre relativo. Um processo pode ser, e é muitas vezes, um resultado de um outro processo anterior, ao mesmo tempo que gera os seus próprios resultados.

Neste contexto, centrar-nos-emos, agora, nos Processos psicológicos e psico-sociais, isto é, naqueles fenómenos humanos individuais e grupais que, embora sendo fruto e efeito dos Sistemas de Gestão, da Estrutura, da Estratégia e da Tecnologia, ao mesmo tempo, os influenciam e geram nas pessoas e nos grupos uma maneira de sentir, de fazer e de ser (Qualidade dos RR.HH., a nivel individual e grupal) que se repercute na tarefa bem feita e na consecução dos objectivos estratégicos da organização (Efectividade Organizacional). Estes fenómenos impregnam a vida laboral e profissional dos indivíduos e dos grupos, bem como afectam todos os aspectos da vida organizacional. Como afirmava Pinillos, referindo-se à Psicologia, também poderíamos dizer, referindo-nos a estes processos psicológicos e psico-sociais que, embora não sejam tudo na Organização, estão em tudo.

Em primeiro lugar, iremos referir os processos psicológicos que ocorrem a nivel das pessoas enquanto indivíduos. Escusado será dizer que não vamos ser exaustivos, nem descrever todos os processos psicológicos que as pessoas experienciam. Vamos, no entanto, sublinhar alguns muito importantes e significativos, no contexto de trabalho, e que são úteis para dar conta duma parte importante do comportamento dos indivíduos na organização. São os seguintes: Auto-eficácia, percepção da Equidade, Clareza de papéis, Conflito de papéis, Sobrecarga de Trabalho, Instrumentalidade, Conhecimento dos Resultados, Conhecimento da Responsabilidade pelos Resultados, Conhecimento do Significado do trabalho e percepção do Apoio Social. São numerosos os autores que falam destes processos e cujos contributos nesta matéria reconhecemos, embora não citemos, aqui, a contribuição particular de cada um deles (Bandura, Vroom, Adams, Hackman e Oldham, etc.).

Para além destes Processos Psicológicos, outros de carácter mais marcadamente social ocorrem e a esses chamaremos Psico-sociais. Afectam os grupos e têm que ver com fenómenos intra-grupais, que se produzem no interior de unidades e grupos de trabalho, assim como com fenómenos inter-grupais, produzidos entre grupos, e que acabam por afectar toda a organização. Uns são mais globalizantes do que outros, incluindo no seu interior 
outros de menor alcance. Todos estão interligados. Os mais importantes, na nossa opinião, são os a seguir indicados. Partindo dos mais globalizantes, teremos, em primeiro lugar, a Cultura Organizacional e os processos de Mudança Organizacional (que incluem nos seus aspectos mais complexos a Mudança de Cultura Organizacional). Talvez menos globalizantes que os anteriores, mas também muito importantes, teremos os seguintes: a Liderança, a Grupalidade ou Nivel de Desenvolvimento Grupal dos grupos formais de trabalho, a Participação, o Poder, o Conflito, a Tomada de Decisão e os processos de Negociação.

Um outro processo psico-social globalizante que incluiremos entre os que definimos como processos/resultados nas pessoas e nos grupos é o Clima. Ainda que o Clima também possa ser considerado como gerador de atitudes face ao trabalho e de outros processos/resultados, como a Motivação ou a Implicação (Compromisso), considerá-lo-emos como resultado dos anteriormente assinalados e como fazendo parte da Qualidade dos RR. HH. da organização.

\subsubsection{QUALIDADE DOS RECURSOS HUMANOS (PROCESSOS/RESULTADOS)}

Centrar-nos-emos, agora, nos resultados que a Gestão dos RR.HH. procura obter relativamente às pessoas, qualquer que seja a organização. Trata-se daquilo a que chamámos Qualidade dos seus RRHH. Esta tem componentes a nível individual, a nível grupal e a nível organizacional. A maior ou menor qualidade dos $R R H H$. de uma organização irá determinar os resultados das pessoas e dos grupos para essa organização, o que constituirá a Efectividade Organizacional.

Começaremos por dar atenção aos aspectos que constituem a Qualidade dos RR.HH. da organização, a partir duma perspectiva individual, e, como é óbvio, considerando que as pessoas são empregadas e profissionais que trabalham numa e para uma organização. Não faremos, pois, qualquer referência à sua qualidade enquanto pessoas humanas, questão que não discutimos e que não está incluída nos objectivos do nosso trabalho. Assim, um indivíduo particular poderia ter, por exemplo, uma elevada qualidade como pessoa (o que não avaliamos em nenhum momento) e, ao mesmo tempo, essa característica coexistir com uma baixa qualidade enquanto empregado da organização, dado não ter as competências e os conhecimentos requeridos para fazer bem o seu trabalho, na função que lhe está atribuida. 
Uma vez esclarecido este ponto, entre as dimensões que constituem a Qualidade dos RR.HH. duma organização — ao nível dos indivíduos — distinguiremos as que estão de forma mais directa e linear relacionadas com os resultados das pessoas para a organização (trabalho bem feito: resultados e desempenhos: absentismo; taxa de acidentes; "turnover") de outras cuja relação com aqueles resultados melhor se exprime através de funções matemáticas, quer estas curvilíneas ou de outro tipo. Relativamente às primeiras, pode dizer-se que. em geral, um nível mais elevado na dimensão corresponde a melhores resultados do indivíduo para a sua organização. Quanto às segundas, a relação não segue esta função e não pode ser estabelecida uma relação directa nem inversa (mais, mais; mais, menos), mas antes de um outro tipo, como por exemplo: ultrapassado um certo nível, já não influencia; níveis altos e baixos influenciam negativamente e níveis médios positivamente, etc.Vejamos isto de maneira mais concreta.

As dimensões do primeiro grupo são as seguintes: Motivação, Identificação e Implicação (Compromisso) com a Organização, Envolvimento no trabaIho e nivel de Competências. Destas características pode dizer-se que quanto mais elevado o nivel que atingem, melhores serão os resultados que se obtêm dos indivíduos para a organização, melhor será o seu desempenho e menor o seu absentismo, a taxa de acidentes e o "turnover".

As dimensões do segundo grupo contemplado são as seguintes: Stress, Activação e Burn-out, Satisfação no Trabalho e Qualidade de Vida Profissional. A sua relação com a Efectividade Organizacional não é linear. Elevados ou baixos níveis de Stress, por exemplo, prejudicam o rendimento ou o desempenho, enquanto um nível moderado do mesmo o beneficia. Do mesmo modo, elevados níveis de Satisfação no Trabalho não asseguram elevados niveis de produção ou desempenhos elevados, embora baixos níveis de satisfação conduzam as pessoas a boicotar o desempenho e a render menos no seu trabalho.

Resumindo, o diagnóstico da Qualidade dos RR.HH. duma organização 196 passa - ao nível dos indivíduos - por avaliar e estabelecer o seu nivel de Competências, a sua Motivação, a sua Identificação e Implicação com a Organização, o seu Envolvimento no trabalho. Importa, ainda, completar esta informação com a avaliação do seu nível de Stress, Activação ou Burn-out, o seu nível de Satisfação no Trabalho, bem como o da sua Qualidade de Vida Profissional. Tudo isto é muito importante tendo em vista o seu desempenho e a obtenção da Efectividade Organizacional. 
Considerando o nivel grupal, além do relacionado com a Identificação dos indivíduos com a Organização (considerada no plano individual, mas tendo uma clara dimensão grupal), importa assinalar o Clima grupal e o nível de Funcionamento dos grupos formais como Equipas de Trabalho (ou a adequação das qualidades grupais às exigências da tarefa). Se considerarmos o nível organizacional, a Qualidade dos RR.HH. da empresa pode ser relacionada com o Clima Organizacional e. em certo sentido, com todas as outras dimensōes (nivel de motivação global do pessoal da empresa, de competências, de stress, etc.), mas, nesse caso, importaria prestar a devida atenção a todos os problemas que suscita a agregação de medidas para a avaliação de variáveis a nível organizacional. Neste sentido, vale a pena referir a evolução do conceito e da medida de Auto-eficácia, que Bandura (1997, 1998) propõe como Eficácia Colectiva.

\subsubsection{EFECTIIDADE ORGANIZACIONAL (RESULTADOS DAS PESSOAS PARA A ORGANIZAC̄ĀO)}

Todas as dimensões do modelo de comportamento organizacional até ao momento tratadas têm como finalidade a obtenção da Efectividade Organizacıonal. Ora este é um conceito susceptível de múltiplas interpretaçōes, não tendo o mesmo significado em todas as organizações. Por se tratar de um juízo de valor que pode afectar muitas dimensões, apoia-se em outros tantos critérios de valor que, perante cada circunstância concreta, devem ser explicitados. Contudo, apesar de cada organização poder escolher e entender de forma diversa a sua Efectividade, podemos descrever uma serie de critérios comuns a todas elas que sejam susceptiveis de se adaptarem a diferentes formas de entender a Efectividade. De entre esses critérios, cada organização irá escolher os que irão constituir a sua forma concreta e peculiar de a entender.

Na elaboração da nossa conceptualização da Efectividade Organizacional inspiramo-nos em numerosos autores (entre outros, Etzioni, 1964: Katz \& Kahn, 1977; Cameron, 1978; Van de Ven \& Ferry, 1980; Veciana, 1981; Gibson, Ivancevich \& Donnelly, 1983; Cameron \& Whetten, 1983; Cameron, 1986; García, 1989; Brinkerhoff \& Dressler, 1990; Menguzzato \& Renau, 1991: Pritchard, 1992: Sánchez 1992a, 1992b).

Em primeiro lugar, podemos pensar (ou construir) a Efectividade Organizacional como o resultado da Eficácia e da Eficiência da empresa. Definiríamos Eficácia como a relação outputs conseguidos/outputs esperados ou standards 
$(\mathrm{O} / \mathrm{S})$ e Eficiência como a relação outputs conseguidos/inputs utilizados (O/I). O conceito de Eficiência incluiria os custos e/ou os recursos utilizados para conseguir os outputs ou objectivos prosseguidos, aspecto que, a par do de Eficácia, completaria de forma importante o conceito de Efectividade.

Em segundo lugar, os critérios básicos de Efectividade que identificámos foram fornecidos pelos modelos mais significativos existentes: o modelo dos objectivos: o modelo dos sistemas: o modelo dos componentes múltiplos: - modelo dos valores concorrentes, como tentativa de síntese dos anteriores. Uma ampla exposição e comentários críticos sobre os mesmos encontra-se no livro de Fernández-Ríos \& Sánchez (1997) Eficacia Orgonizacional. Concepto, desarrollo y evaluación.

Os diferentes modelos respondem a diversas formas de conceber e de observar as organizações: como sistema racional (modelo dos objectivos). como sistema aberto (modelo dos sistemas) e como sistema político (modelo dos componentes múltiplos). Cada um deles incide, em maior ou menor grau, sobre os três momentos chave do funcionamento organizacional: 1) A efectividade na aquisição de recursos. 2) A efectividade no processo ou processos de transformação. 3) A efectividade na consecução de resultados de diverso tipo.

A partir de uma perspectiva mais concreta, a avaliação da Efectividade faz referência a critérios específicos, sobre os quais foram apresentadas diversas listagens, propostas por diferentes autores (Campbel, 1977; Van de Ven \& Ferry, 1980; Quinn \& Rohrbaugh, 1983; Peiró, 1990; Sánchez, 1992a; Fernández-Ríos \& Sánchez, 1995, etc.). Com base nestas propostas, o nosso modelo de comportamento organizacional contempla uma multiplicidade de critérios, agrupados em diferentes categorias, que remetem para diferentes níveis da organização: o individual ou do posto de trabalho, o grupal ou dos grupos, unidades e/ou departamentos, e o organizacional. Também os referidos critérios incluem não só os resultados dos indivíduos para a organização, como também os processos/resultados nos indivíduos ou Qualidade de RR.HH.

198 A nível individual, como resultados dos indivíduos para a organização, contemplámos dois critérios positivos a potenciar e três negativos a reduzir, a que já aludimos anteriormente. Positivos: os resultados alcançados com o trabalho e os desempenhos ou a forma de trabalhar (trabalho bem feito). Negativos: a taxa de acidentes, o absentismo e o abandono da empresa (este último é especialmente sensível, dado ser valorizado de modo diferente, consoante a politica e a estratégia da organização). Como processos/resultados nos indiví- 
duos que afectarão os anteriores, consideramos, a este nível, as dimensões da Qualidade dos seus RR.HH. ao nível dos indivíduos, que atrás expusemos.

A nível grupal, como resultados das pessoas para a organização, consideramos a consecução dos objectivos da tarefa, ou os resultados obtidos pelos departamentos ou grupos, e como resultados nos grupos, o clima grupal e o adequado funcionamento como equipas de trabalho (no nível exigido pelas características contingentes da tarefa).

A nível organizacional, por fim, o qual inclui e se fundamenta nos níveis anteriores, consideramos múltiplos critérios, agrupados em diferentes categorias: Económicos: financeiros, produtivos e comerciais; Sociais: internos e externos; Ecológicos: cumprimento de normas e aproveitamento de energias: Outros: flexibilidade e captação de recursos.

\subsubsection{FEED-BACK E RELAÇŌES}

Descritos os elementos que compōem o Modelo de Comportamento Organizacional em se apoía $\circ \mathrm{ASH}$ e, apesar de termos referido repetidas vezes a relação de interdependência entre todos eles, talvez pudesse alguém continuar a concebê-los como elementos justapostos e desconectados. Não é assim que acontece.

O Meio envolvente influencia a Organização, mas esta não só se adapta a ele de forma reactiva, como também o transforma activamente, influenciando-o e configurando-o de uma determinada maneira. Dizer, por exemplo, que as Organizações se "encontram imersas num meio altamente competitivo" (como já estamos cansados de ouvir) é demasiado simples, visto serem elas próprias que o constróem assim. Quando o interpretam deste modo e o pensam em termos competitivos, estão a actuar de forma competitiva e contribuem para o configurar com estas características. Esquecem-se, muitas vezes, que elas são responsáveis por esse Meio envolvente em que se encontram imersas. A última ou a primeira seta do feed-back que surge da EFO para o Meio envolvente pretende, de algum modo, lembrar esta realidade. A Organização que constrói automóveis modifica a Envolvente, não só física e económica, mas também comportamental e social.

Logicamente, as mudanças que com a sua EFO uma Organização gera no seu Meio envolvente serão objecto de uma nova análise. tendo em vista 
a redefinição da sua Estratégia, num processo circular, sempre inacabado; a Estratégia irá configurar, de novo, a Tecno-Estrutura e os Sistemas, que, por sua vez, irão gerar novos Processos Psicológicos e Psico-sociais, os quais irão provocar novos resultados nas pessoas (configurando a sua qualidade como profissionais e como trabalhadores); estas pessoas, com o seu comportamento, irāo produzir resultados para a organização, sendo, de novo, contribuintes e constituintes da sua EFO. A EFO duma organização confirma o sucesso ou o insucesso da sua Estratégia e proporciona dados para a sua redefinição.

Apesar de algumas setas do modelo poderem sugerir uma relação sequencial e até linear entre as suas dimensōes, a realidade não é essa, visto todos os elementos agirem muitas vezes simultaneamente uns sobre os outros, com relações circulares e nem sempre lineares, desenhando aquilo que, finalmente, poderia resultar num complexo tecido de interligaçōes, expressando a complexidade do sistema social. Logicamente, a concretização em modelos matemáticos cada vez mais precisos obrigar-nos-á a focar partes reduzidas do sistema e a propor as interligações dos seus elementos, traduzidas em hipóteses relacionais, e, quando for o caso, em equações estruturais específicas. Por exemplo, será necessário estabelecer um modelo mais preciso sobre o modo como determinados processos psicológicos e psico-sociais (conflito de papéis, ambiguidade de papéis, sobrecarga de trabalho, apoio social, nivel de desenvolvimento grupal, etc.) influenciam o nível de stress dos trabalhadores e as consequências que esse nivel tem no desempenho, a satisfação no trabalho, o absentismo e a taxa de acidentes. Ou, ainda, o modo como determinados aspectos dos Sistemas de Gestão (por exemplo, a Remuneração ou a Avaliação de Desempenho) geram percepções de equidade ou de inequidade, de instrumentalidade, conhecimento de resultados, etc., o que irá influenciar decisivamente a motivação dos trabalhadores ou outros processos/resultados.

A exigência de parcimónia, por um lado, e o nivel de análise, geral e glo200 bal, por outro, obrigam-nos a simplificar o número e a descrição das relações entre as diferentes dimensões - identificadas como fundamentais - do comportamento organizacional. 


\section{O ASH COMO AUDITORIA DE RECURSOS HUMANOS: DESCRIÇẢO}

\subsection{UM INSTRUMENTO ÜTIL PARA OS NOVOS DESAFIOS COLOCADOS Ȧ GESTÃO DE RR,HH.}

Relativamente aos desafios postos aos Gestores de RR.HH. pelo século que se aproxima, diversos autores (Dolan \& Valle, 1998; Gómez-Mejía, Balkin \& Cardy, 1995) descrevem alguns dos traços que irão caracterizar os profissionais bem sucedidos. Terão que ser, realmente e em todo o seu sentido, profissionais e capazes de mostrar o valor acrescentado da gestão que praticam. Deverão conhecer e saber usar as Novas Tecnologias na Gestão integrada de RR.HH., bem como desenvolver uma gestão Internacional e Multicultural sobre pessoas muito diversas. Terão de mostrar a sua eficiência na prestação de serviços aos seus clientes internos, por comparação com outras companhias exteriores e, finalmente, modificarão o seu papel tradicional. Gostaria de comentar algumas destas características, em particular o carácter profissional do Director de RRHH., a sua capacidade de demonstrar o valor acrescentado da sua gestão e o seu novo papel.

Quando Peiró (1994) e outros (Blanco \& Fernández Ríos, 1989) assinalam as características de uma intervenção profissional nas organizações referem-se a várias dimensões que a caracterizam. Uma intervenção profissional baseia-se em teorias comprovadas cientificamente e utiliza tecnologias e técnicas fundamentadas naquelas, que sejam susceptiveis de serem comunicadas e ensinadas a outros profissionais. Relacionada com os objectivos da Organização, a sua intervenção realiza-se numa perspectiva sistémica, grupal e não individual. $O$ profissional que intervém é. além do mais, eticamente responsável e costuma estar vinculado a um Colégio ou Ordem Profissional, que zela pelo adequado e correcto comportamento dos seus membros, do ponto de vista técnico e moral.

Neste sentido, se o Director de RR.HH. tem de ser um profissional reconhecido, terá que basear a sua gestão no conhecimento teórico, comprovado cientificamente, e no uso de tecnologias apropriadas a esse mesmo conhecimento. E que conhecimento teórico é o mais apropriado ao seu âmbito de competências? Uma vez que a sua gestão se centra na direcção de pessoas (e não de dinheiro, materiais ou máquinas), parece razoável que o conhecimento mais importante de que ele irá precisar se situe no âmbito das Ciências do Comportamento Humano, individual e social (Psicologia, Sociologia. 
Antropologia). Além disso, visto tratar-se de um comportamento inserido em organizações, deverá ser conhecedor, também, na medida em que o afectam, das ciências que tratam dos fenómenos que o influenciam e o acompanham (Teoria Organizacional e Administração, Engenharia organizacional, Economia e Direito).

Por outro lado, se o seu conhecimento é profissional, disporá de tecnologias comprovadas que the permitam medir e diagnosticar o estado presente dos sistemas e processos humanos na organização, bem como os efeitos da sua intervenção, nos termos apropriados da área do seu conhecimento. $\mathrm{Na}$ realidade, só a partir dessa capacidade poderá demonstrar, no seu caso, o valor acrescentado da sua gestão e intervenção, verificando através de metodologia adequada o antes e o depois da mesma. Por outro lado, relativamente à sua visão dos problemas organizacionais, mesmo quando centrados numa área particular, estes deverão ser abordados numa perspectiva sistémica, em ligação com a estratégia e o funcionamento global da organização.

Relativamente ao seu papel, Gómez-Mejía, Balkin \& Cardy (1995) definem-no assim: "O papel de um departamento de recursos humanos de uma organização é apoiar - e não substituir - as responsabilidades dos "managers", relativamente aos recursos humanos. Por exemplo, o departamento de RR.HH. pode desenvolver uma forma de ajudar os "managers" a medir o desempenho dos subordinados, mas são os "managers" que conduzem a verdadeira avaliação... Isto significa que cada "manager" é um director de recursos humanos... Mais do que desempenhar uma função de staff (os profissionais de RR.HH.), deverão ser considerados como consultores internos, conhecidos pela sua experiência e competência para ajudar a resolver os problemas de RR.HH. com que os directores de linha (line) se confrontam. Deverão, ainda, ser capazes de ligar de forma efectiva as actividades de RR.HH. às necessidades de negócio da firma" ( $p$. 35). Este último ponto assinala um outro aspecto do papel do Director de RR.HH. empenhado na Efectividade

202 Organizacional como responsável pela Estratégia de gestão de pessoas, com vista à sua contribuição para os objectivos estratégicos da organização em que participa.

Perante estas necessidades e desafios, o ASH está concebido (e, em parte, realizado) como um instrumento de ajuda ao Director de RR.HH. (ou ao consultor) e é composto por um conjunto de escalas e de questionários que deverão reunir as seguintes características: 1) Baseados num Modelo Teó- 
rico de Comportamento Organizacional apoiado em teorias científicas de diferente importância e nível (de nível individual, grupal, organizacional e societal). 2) Capazes de medir, de forma válida e fiável, os constructos abrangidos e contempladas por essas diversas teorias, podendo usar-se como tecnologias de diagnóstico (de um diagnóstico que, no caso que nos ocupa, é já uma intervenção). 3) Que facilitem uma visão sistémica e global da organização, adequada à complexidade desta, que permitam a análise e a avaliação de algumas dimensões fundamentais, assim como da sua interacção e integração mútua, tal como tem sido proposto pelos modelos integrados de Avaliação Organizacional. 4) Que contribuam para a avaliação do impacto que os Sistemas de Gestão de RRHH têm nas pessoas e dos efeitos que nelas produzem determinadas decisões estratégicas, mudanças e/ou intervenções realizadas na organização, assim como na Efectividade Organizacional. 5) Que proporcionem informação quantitativa sobre fenómenos objectivos e subjectivos, susceptível de ser analisada e tratada informaticamente. 6) Que sejam reduzidos e que possam ser aplicados de forma breve e em tempo razoável para a empresa.

\subsection{AUDITORIAS DE RR.HH.E CONTRIBUIÇÕES DO ASH: ÁREAS QUE COBRE}

Após uma revisão de diversas definições de Auditoria Social aplicada aos RR.HH. da empresa (Stephens, Vatier, Ravalec, Candau, Couret \& Igalens), Nevado (1998) propõe a seguinte: a Auditoria Social é um instrumento de gestão social que, utilizando metodologias e ferramentas semelhantes às aplicadas em outras auditorias, permite uma melhor administração, gestão, eficácia e eficiência dos recursos humanos da empresa.

Para Nevado (e nós partilhamos da sua posição), o objectivo das Auditorias de RR.HH, é contribuir para a Efectividade Organizacional, não só funcionando como sistema de controlo do que presentemente está a acontecer e está a ser realizado, mas também como ferramenta de previsão que visa diminuir os riscos futuros e melhorar a performance social, assim como a contribuição da função pessoal para a efiçácia geral da empresa. Uma vez que está centrada sobre a função pessoal, a auditoria não pode observar e medir o objecto auditado sem o modificar, devendo incluir, entre as suas medidas, questões qualitativas referentes a aspectos que não são de fácil medição. Além disso, os seus resultados são mais difíceis de interpretar que noutras 
matérias, devido, entre outras razões, ao facto de existirem poucos indicadores que tenham sido aceites por todos. Segundo o mesmo autor, toda a Auditoria deve contar com os seguintes elementos: Deve dispor de referenciais adequados, ser capaz de descobrir problemas potenciais com base nos desvios dos resultados relativamente aos referenciais mencionados, deve realizar-se em estreita cooperação com os auditados e terá que utilizar instrumentos próprios da psicologia e/ou sociologia (e, provavelmente, de mais ciências).

Os campos de aplicação das Auditorias Sociais de RR.HH. podem ser vários, centrando-se na função de pessoal, no seu conjunto, quer nos Sistemas de Gestão de RR.HH. (Seleç̧ão, Formação, Retribuiçōes, etc.), quer nos Processos/Resultados produzidos nas pessoas ou Qualidade dos Recursos Humanos (Motivação, Identificação, Implicação, etc.), quer nos Resultados das pessoas para a Organização (Absentismo, Taxa de Acidentes, Abandono da empresa, Quantidade e Qualidade do trabalho realizado, Desempenhos), quer nos aspectos organizacionais (falámos de processos Psico-sociais, tais como a Cultura, a Liderança, o Desenvolvimento Grupal, etc.), quer na coerência e integração de todos eles e deles com a Estratégia, a Tecnologia e a Estrutura da empresa. Nesta mesma linha, encontra-se a definição proposta por Cantera (1996), que se inspira em Harper \& Lynch (1992). Peretti \& Vachetie (1985) e EGG (1987).

Nevado distingue três níveis de realização da Auditoria Social de RR.HH. nas empresas: I) a Auditoria de Cumprimento (ou Conformidade); 2) a Auditoria Operacional ou de Eficácia e 3) a Auditoria Estratégica. A primeira é de natureza jurídica e centra-se na inventariação da situação social da empresa. tendo em conta as normas do Direito do Trabalho e verificando com regularidade a sua relação com a regulamentação aplicável. Observa se são cumpridas as obrigações sociais, financeiras (Segurança Social) e informativas (Comité da empresa) da empresa, e verifica se as relaçōes dos trabalhadores com a empresa estão conformes aos estatutos jurídicos. Na realidade, poderia

204 dizer-se que se trata de uma Auditoria das Relações Laborais da Organização.

A Auditoria Operacional ou de Eficácia centrar-se-ia no que designámos por Sistemas de Gestão de RR.HH., Processos/Resultados nas Pessoas e nos Grupos, custos sociais e económicos derivados de um mau funcionamento dos mesmos. Por último, a Auditoria Estratégica analisaria se as políticas de pessoal são adequadas aos objectivos gerais e específicos da empresa, atendendo à Estratégia da mesma. Ambas, a Operacional e a Estratégica, se cen- 
trariam no que denominámos o Sistema Global Integrado de RR.HH. da empresa. Naturalmente, como aponta Nevado, estes três niveis são teóricos, pois, na prática, o auditor deverá tê-los presentes no seu conjunto, detectando disfuncionamentos possíveis e dando a cada um dos três a importância que as circunstâncias da empresa requerem.

Finalmente, há que sublinhar que toda a auditoria deve dispor de um Sistema de Referência, ou Referencial, ou Norma Standard, sobre o qual assenta a credibilidade do trabalho do auditor; sistema que, no caso da Auditoria de $\mathrm{RR}$. HH., se torna mais complexo pelas razões antes apontadas. Existem diferentes propostas referenciais. Entre outras, podem ser consultadas as de Nevado (1998), da EGG (1994) e do COP/IE'93. Logicamente, subsistem nelas zonas que ficam nas suas junções, pois, como aponta Nevado, um sistema geral de referência que cubra totalmente o campo dos RR.HH. não existe, por numerosas razões que este autor expõe e que não vamos reproduzir agora. Depois do que ficou dito, o leitor pode compreender perfeitamente o fundamento desta afirmação.

Neste contexto, $\circ$ ASH poderia definir-se como um Sistema de Auditoria do Sistema Humano das Organizações, não de Cumprimento, centrado nas relações laborais, mas sim na área Operacional ou de Eficácia e Estratégica. O ASH cobre os seguintes campos: I) Os Sistemas de Gestão de RR.HH., quase na sua totalidade (com excepção, por enquanto, do de Planeamento de RR.HH. e do de Identificação de Potenciais e Planos de carreira), assim como a Integração dos mesmos entre si e com os objectivos e a Estratégia da empresa. 2) Os Resultados/Processos nas Pessoas, ou Qualidade dos RR.HH., nos diferentes niveis da organização (Motivação, Identificação, Implicação, etc., incluindo o Clima). 3) Cinco Processos Psico-sociais (para além do Clima): Cultura, Desenvolvimento dos grupos formais, Participação, Liderança e factores facilitadores ou inibidores dos Processos de mudança. 4) Identificação dos critérios escolhidos e medida da Efectividade Organizacional, com vista à quantificação e análise do impacto e contribuição da Gestão de RR.HH. para a referida Efectividade. Mede, também, a convergência entre os critérios dos empregados e os da Direcção, facilitadores ou inibidores da implicação e da identificação com a organização. 


\subsection{ALGUNS APONTAMENTOS SOBRE A VALIDADE E A FIABIUDADE DO ASH}

No que diz respeito aos Sistemas de Gestão, os diferentes questionários foram elaborados com a ajuda e a orientação de dois consultores, peritos em cada um deles, com o fim de especificar os aspectos nucleares dos mesmos e de assegurar a sua validade de conteúdo. No que diz respeito aos questionários de Qualidade dos RR.HH., estes foram elaborados a partir de outros instrumentos (já construídos anteriormente e comprovados por diversos autores espanhóis ou estrangeiros), de que, por vezes, utilizámos alguns itens e nos quais, outras vezes, nos inspirámos para a própria elaboração de itens mais adaptados ao nosso contexto, ou ao nosso modo de entender os conceitos considerados.

Com todos os inquéritos referentes à Qualidade dos RR.HH. trabalhámos no mesmo tipo de análise, com o fim de estudar a sua fiabilidade e validade psicométricas. Primeiro, efectuámos uma análise de frequências de todos os itens, para verificar a sua idoneidade relativamente à distribuição das respostas. Segundo, e para cada dimensão estabelecida o priori, uma análise factorial - de factor comum único - com o fim de estudar as contribuições dos diferentes itens para esse factor e a percentagem de variância explicada pelo mesmo. Terceiro, análises factoriais - exploratórias ou confirmatórias, mediante pedido de um determinado número de factores - das escalas que continham mais do que uma dimensão estabelecida $a$ priori. Quarto, análise de frequências dos diferentes indicadores gerados pelas diferentes escalas. Quinto, utilização de análises de correspondências para o estudo do funcionamento destes indicadores, para verificar se neles ocorria o efeito Guttman (sinal da correcta distribuição dos valores dos indicadores). Sexto e último, múltiplos estudos correlacionais - coeficientes de correlação e também análises de correspondências - entre os diferentes indicadores gerados no ASH, que, embora conceptualmente diferentes, estão relacionados entre si ( $p$. ex."

206 é lógico pensar que as pessoas altamente motivadas no seu trabalho, também estejam altamente empenhadas nas suas empresas, apresentem altos níveis de satisfação e de qualidade de vida, e níveis moderados ou baixos de stress ou burnout).

A título de exemplo, na tabela I, apresentámos alguns resultados psicométricos sobre alguns dos tópicos trabalhados no ASH. Embora apresentemos o valor alfa de Cronbach para as diferentes sub-escalas (por evidentes 


\begin{tabular}{|c|c|c|c|c|c|}
\hline Tópica & Indicodores & $\begin{array}{l}\text { Tomanho } \\
\text { Amostra }\end{array}$ & $\begin{array}{c}N^{\circ} \text { itterms } \\
\text { por indicodor }\end{array}$ & $\begin{array}{c}r \text { de } \\
\text { Kendall }\end{array}$ & $\begin{array}{c}\alpha \text { de } \\
\text { Cronboch }\end{array}$ \\
\hline \multirow[t]{8}{*}{ Motivaçāo } & Necessidades & 144 & (1) & $.3367(2)$ & \\
\hline & Instrumentalidade & 144 & (3) & $.5061^{(4)}$ & \\
\hline & Auto-eficácia & 144 & 4 & & .6648 \\
\hline & Equidade & 144 & 2 & .6441 & \\
\hline & Conhecimento dos resultados & 144 & 2 & .3158 & \\
\hline & Responsabilidade pelos resultados & 144 & 2 & .3210 & \\
\hline & Significado percebido do trabalho & 144 & 2 & 1109 (5) & \\
\hline & Nivel de motivação & 144 & (b) & $\begin{array}{l}.3856 \\
.4953 \mathrm{~m}\end{array}$ & \\
\hline \multirow{5}{*}{$\begin{array}{l}\text { Implicação } \\
\text { e identificação com } \\
\text { a Organização }\end{array}$} & Implicação por necessidade & 144 & 3 & & .8120 \\
\hline & Implicaçăo por troca & 144 & 3 & & .6712 \\
\hline & Implicação afectiva & 144 & 3 & & .8021 \\
\hline & Implicação de valores & 144 & 3 & & .7087 \\
\hline & Identificação com a organização & 144 & 15 & & .9282 \\
\hline Satisfaçäo & Satisfação geral & 230 & 15 & & .9077 \\
\hline Stress, & Stress & 144 & 5 & & .7568 \\
\hline Activação e & Activaçăo & 144 & 5 & & .8085 \\
\hline Burnout & Burnout & 144 & 5 & & .7819 \\
\hline \multirow{6}{*}{$\begin{array}{l}\text { Qualidade de } \\
\text { vida } \\
\text { profissional e } \\
\text { alguns } \\
\text { processos } \\
\text { psicológicos } \\
\text { relacionados. }\end{array}$} & Conflito de papéis & 144 & 2 & .2851 & \\
\hline & Ambiguidade de papéis & 144 & 2 & .5552 & \\
\hline & Sobrecarga de trabalho & 144 & 2 & .4784 & \\
\hline & Saúde em geral & 144 & 2 & .2226 & \\
\hline & Lazer & 144 & 2 & .4075 & \\
\hline & & & & & \\
\hline
\end{tabular}

(1) A mediçáo de necessidades è realizada através de dois tipos de escalas. Na primeira, o sujeito escolhe entre dois protótipos de trabalho, de acordo com as suas preferências (semelhante ás secçóes I e 6 da forma A do JDS. mas com itens diferentes). Na segunda, atribui um valor ao grau de importincia que para ele tem cada uma das necessidades. A primeira escala abrange 21 itens, pelo facto de comparar entre si sete tipos de necessidades diferentes. A segunda conta com 7 itens, um para cada necessidade.

(2) Retivemos a média da correlaçáo entre as duas escalas referidas. O valor é muito semelhante ao encontrado noutros estudos com formatos de escalas semelhantes (ver, Fortea e Fuertes. 1997).

(3) O questionário tinha dois itens para cada instrumentalidade (sete instrumentalidades).

(4) Obtivemos o valor médio das correlaçôes das sete instrumentalidades. Ou seja, cada par de itens que mede uma mesma instrumentalidade está correlacionado e do conjunto dos sete coeficientes de correlaçáo obtivernos o seu valor médio.

(5) $\mathrm{Na}$ nova versão do questionário de motivação mudámos um dos itens que estava formulado em sentido inverso e que parecia nåo ser bem entendido, segundo os resultados. Por outro lado, é este o único coeficiente não significativo, em termos estatisticos.

(6) O Nivel de Motivaçăo ou Indice de Motinação Efectiva (IMEF) é o fruto de considerar todos os aspectos previamente comentados (as necessidades e as suas correspondentes percepçōes de instrumentalidade, a auto-eficícia, a equidade, o conhecimento dos resultados, a consciência de responsabilidade pelos mesmos e o significado percebido) num indicador único e final de motivaçăo, mediante uma formulaçăo matemática.

(7) Obtivemos a correlaçāo do IMEF com dois critérios externos. Primeiro, com um indicador resultante da soma das duas questóes seguintes: "Sinto-me motivado - com vontade de me esforçar - no meu trabalho" e "No meu trabalho, tenho vontade de trabalhar bem e de alcançar resultados". O segundo, um indicador também resultante da soma das cinco caracteristicas do trabalho de Hackman \& Oldham, que sảo formuladas da seguinte forma: "No meu trabalho, as outras pessoas podem-me identificar como o autor de um determinado produto ou serviço", "No meu trabalho desenvolvo uma importante variedade de tarefas", "Eu costumo receber informaçâo sobre os resultados do meu trabalho", "No meu trabalho tenho autonomia ou liberdade de decisảo" e "O meu trabalho é importante para outras pessoas".

TABELA 1 - Alguns dados de interesse psicométrico sobre alguns dos tópiços incluídos no ASH 
motivos de espaço), lembramos que a nossa estratégia de trabalho habitual tem sido diferente, implicando o estudo factorial de cada um dos tópicos. Isto, para além de contribuir para um estudo mais sério da fiabilidade das escalas, representa uma análise da validade (de constructo) das mesmas. Por outro lado, todos os coeficientes de correlação apresentados são significativos a $99 \%$, com excepção do relativo ao significado percebido.

\section{O ASH E O SEU CONTRIBUTO PARA OS MODELOS DE QUALIDADE}

A Fundação Europeia para a Qualidade indicava, nas suas recomendaçōes sobre a forma como as empresas deveriam auto-avaliar-se, vários pontos importantes: fornecer informação concisa e factual, fornecer alguma quantificação (grau de implantação de cada sub-critério, aos diferentes níveis de análise da organização) e mostrar a conexão entre os diferentes critérios avaliados (agentes e resultados).

Não seria bom saber se, realmente, os valores atribuídos pela EFQM às variáveis agentes do seu modelo correspondem à influência real que tais variáveis têm nas que se referem a resultados ou efectividade organizacional? Por outro lado, não seria útil, a tais instituições, aproveitar determinados instrumentos cientificamente elaborados para completar a avaliação de certas variáveis, medidas de forma mais qualitativa? De facto, o ASH está desenhado para fornecer uma ampla informação fiável e válida sobre algumas das variáveis (ou aspectos das variáveis) do modelo da EFQM, tais como Liderança e, sobretudo, Gestão de Pessoal e Satisfação do Pessoal. E, em menor medida, mas também de forma clara, sobre Resultados do Negócio (Critérios Económico-Financeiros, Produtivos e Comerciais) e sobre o Impacto na Sociedade.

$\mathrm{O}$ ASH permite fornecer informação quantitativa a este respeito e analisar a relação existente e suposta entre dimensões agentes e outras considera208 das como resultados da organização. Permite, ainda, mostrar a evolução dessa relação ao longo de períodos de tempo determinados. Utilizado em larga escala por numerosas empresas, permitiria identificar a percentagem de variância dos resultados explicada pelas variáveis agentes do modelo. Isto permitiria que se fosse ajustando progressivamente $\circ \mathrm{ASH}$, na sua primeira parte (agentes), e modificando, se fosse preciso, os valores (pontos) atribuídos a cada dimensão, com base na sua influência real (e não apenas suposta) sobre 
os resultados, ou, até, permitiria acrescentar ou suprimir certas dimensões, na sequência e em consequência da investigação. Permaneceria, apesar de tudo. como critério discricional, baseado nos valores defendidos pelas diversas instituições promotoras dos Prémios de Qualidade, o peso atribuído, na pontuação total, às variáveis resultantes ou resultados ( $50 \%$ na EFQM), que, provavelmente, e de forma irreversível, continuarão a ser as quatro actuais: Satisfação do Pessoal ( $9 \%$ na EFQM). Satisfação do Cliente (20\% na EFQM), Impacto na Sociedade ( $6 \%$ na EFQM) e Resultados do Negócio (I5\% na EFQM). Finalmente, é este o modo como a EFQM, com base nos seus valores, constrói o seu conceito de Efectividade Organizacional e convida as organizações europeias a construi-lo.

\section{REFERÊNCIAS BIBLIOGRÁFICAS}

AEDIPE (1998) Encuesta Sociolaboral de Catalunya. Informe Anual 1997. InformAedipe. Edició especial Catolunya. septiembre 1998.

AMARO, R (1981) Administración de Personal. México. Limusa.

ARAGONÉS, R. (1997) Comercio electrónico. ¿Revolución o espejismo virtual? Distribucion $y$ consumo. $n^{\circ} 35$, agosto-septiembre. Pp. 20-24.

ARMSTRONG. M. (1991) A handbook of personnel management practice. Kogan Page.

BESSEYRE DES HORTS. C.H. (1988 a) Vers une gestion stratégique des ressources humaines. Paris: Les Editions d'Organisations.

BESSEYRE DES HORTS, C.H. (1988b) Gérer les ressources humaines dans l'entreprise. Paris. Les Editions d'Organisations.

BLANCO, A. Y FERNÁNDEZ-RÍOS, M. (1989) Psicología Académica y Psicología Profesional en el campo social de las organizaciones. Anuario de Psicología. 41, 2. 75-109.

BRINKERHOFF, R.O. Y DRESSLER, D.E. (1990) Productivity measurement A guide for managers and evoluators. Newbury Park, C.A.: SAGE Publications.

BUENO, E. Y MORCILLO, P. (1990) La dirección eficiente. Madrid.Pirámide.

BYARS, LB.Y RUE, LW. (1991) Human resource management. Homewood: Irwin.

CAMERON. K.S. (1978) Measuring organizational effectiveness in institutions of higher education. Administrative Science Quarterly, 23, 604-632.

CAMERON, K.S.Y WHETTEN, D.A. (1983). Organizotional effectiveness: A comparison of multiple models. New York Academic Press.

CAMERON, KS. Efectiveness as paradox consensus and conflict in conceptions of organizational effectiveness. Management Science, 32, 539-553.

CAMPBELL J.P. (1977) On the nature of organizational effectiveness. En Paul S. Goodman Y J.M. Pennings: News perspectives on orgonizational effectiveness. San Francisco: Jossey-Bass.

CANTERA. F.J. (1996) Del control externo a la Auditoría de Recursos Humanos. In M. Ordoñez (Coord.) La nueva gestión de Recursos Humanos. Madrid. Gestión 2000. Aedipe 
CASCIO, W.F. (1989) Managing human resources: productivity, quality of work life, profits. New York McGraw Hill.

CASCIO. W.F. (1991) Applied Psychology in personnel management. Englewood Cliffs: Prentice Hall.

CHIAVENATO, I. (1981). Administración de Recursos Humanos. México. McGraw Hill.

DEGUY.M. (1989) Politique des ressources humaines dans l'entreprisse. Paris. Les Editions d'Organisations.

DESSLER G. (1988) Personnel Monogement Englewood Cliffs: Prentice Hall.

DOLAN, S.L y BELOUT, A. (1997) Assessing Hurman resource Effectiveness: The Emergence of the Stakeholder Approach. The HRM Research Quarterly, I. (I).

DOLAN. S.L y VALLE, R. (1998) Challenges and Innovations in Managing Human Resources in the Next Century. 4th European Universities Summer School. Seminar 4.1. Barcelona. Fundació Bosch i Gimpera.

DULEBOHN. J.H., FERRIS, G.F. y STODD, J.T. (1995) The history and evolution of human resource management. In Ferris, G.R., Rosen, S.D. y Banum, D.T. (Eds.) Handbook of human resource management. Cambridge. Blackwell.

DUNCAN. RB. (1972) Characteristics of Organizational environements and perceived environmental uncertainty. Administrative Science Quarterly, Vol. $17, n^{\circ} 3$, September, pp. 313-327.

DYER, L y HOLDER, G.W. (1988). A strategic perspective of human resource management. In Dyer. L. (Eds.): Human resource manogement, evolving roles and responsibilities. Washington: Bureau of National Affairs (BNA).

EFQM and EOQ. (1996) The European Quality Award 1997. Application Brochure. European Foundation for Quality Management. Brussels Representative Office. Avenue des Pléiades 15. 1200 Brussels. Belgium.

EGG, G. (1987) Audit des emplois et gestion prévisionnelle des resources humaines Paris. Les Editions d'Organisation.

EMERY, E. \& TRIST, E (1965) The causal texture of organizational environements. Human Relations, vol. 18, pp. $21-32$.

ETZIONI, A. (1964) Modern organizations. Englewood Cliffs, N.J.: Prentice-Hall.

FERNÁNDEZ CAVEDA, A. (1990) La gestión integrada de recursos humanos. Bilbao: Universidad de Deusto.

FERNÁNDEZ-BALLESTEROS, R. (1983) El contexto en evaluación psicológica. In FernándezBallesteros (ed.) Evaluoción de Contextos. Universidad de Murcia, pp. 9-49.

FERNÁNDEZ-RIOS, M. Y SÁNCHEZ I.C. (1997) Eficacia Organizacional. Concepto, desarrollo y evoluoción. Madnd. Díaz de Santos S.A.

FERREIRO, T.Y TANCO, M. (1997) El comercio electrónico en Internet. Distribución y Consumo. $n^{\circ} 35$, agosto/septiembre, pp. 26-30

210 FITZ-ENZ, J. (1984) How to measure human resources manogement New York. McGraw Hill.

FRENCH, W.L (1983) Administroción de Personal. Desarrollo de Recursos Humanos. Méxica. Limusa.

GALBRAITH, J.(1973) Designing Complex Organizations. Nueva York Harper \& Row.

GARCIA, M. (1989) Efectividad Organizacional: concepto y evaluación. Psicologia del Trabajo y de las Organizaciones, $n^{\circ}$ 13, 97-106.

GIBLIN. E.J. (1985) The evolution of personnel. In Gilbertson D.W.Y Stone RJ. (Eds.) Human resource management cases and readings. New York McGraw Hill.

GIBSON, J.L, NANCEVICH, J.M.Y DONNELLY. J.H. (1983). Organizociones: conducta, estructura y procesos. México. Interamericana. 
GONZALEZ. L. (1998) Propuesta de un modelo de Dirección y Gestión de Recursos Humanos. Revista de Trabajo y Seguridad Social. Madrid. Centro de Estudios Financieros (in press)

GOMEZ-MEJÍA L.R. BALKIN. D.B. \& CARDY, R (1995) Managing Human Resources. Englewood Cliffs, NJ: Prentice-Hall.

GOODMAN, P.S., Y PENNINGS. J.M. (1980) Critical Issues in assessing organization effectiveness. In Lawler E.E., Nadler DA, Y Cammann C. (Edit) Organizational Assessment. Nueva York. Wiley.

HENEMAN, H.G., SCHWAB, D.P. FOSSUN. J.A. Y DYER. LD. (1989) Personnel/human resource management. Homewood: Irwin.

HUSENMAN. S. (1985) Gestión de Recursos Humanos. Un enfoque estratégico. Tesis Doctoral. Departamento de Psicología. Universidad Autónoma de Barcelona.

JENKINS, JA. (1974) Remember that old theory of memory? Well, forget it. American Psychologist. 29, pp. 785-795.

KATZ. D.Y KAHN. R.L Psicología social de las organizaciones. México: Trillas.

KAVANAGH, M.j., GUEUTAL. H.G. Y TANNENBAUM. S.I. (1990) Humon resource information systems: development and opplicotion. Boston: Pws-Kent.

LAWLER E.E. NADLER, D.A., Y CAMMAN, C. (1980) Organizational Assessment. Perspectives on the measurement of organizational behovior and the quality of work life. Nueva York. Wiley.

LAWRENCE, P,R Y LORSCH, 1. (1967) Organization and Environement Managing Differentiation and Integration. Homewood, II. Imwin (Trad. en Edit. Labor, 1975)

LEVY-LEBOYER, C. (1979) Psychologie et environment. Paris. Presses Universitaines de France.

MENGUZZATO, M.Y RENAU, J.) (1991) La Dirección estratégica de la empresa: un enfoque innovador del manogement Barcelona. Ariel.

MINER, J.B. (1982) Theories of Organizational Structure and Process. Chicago. The Dryden Press.

MINTZBERG. H. (1979) The Structuring of Organizations: A synthesis of the Research. Prentice Hall Inc. (Trad. castellana en Ariel, 1984)

MISA, K.F.Y STEINT, T. (1983) Strategic Human resource management and the bottom line. Personnel Administrator, Vol. 10. Pp. 27-30.

MUNDUATE. L. (1985) El impacto sociolaboral de las nuevas tecnologias. Temas laborales. Revista andaluza de Trabajo y Bienestar Social, 4. pp.55-70.

MUNDUATE, L (1990) Nuevas tecnologías, automatización y conducta en las organizaciones. In PEIRÓ J.M. (Dir) Formoción e intervención en las Organizaciones. Madrid. Uned.

NEVADO, D. (1998) La Auditoría Social de los Recursos Humanos como Instrumento de Gestión: futuro y limitaciones. Revista de Trabajo y Seguridad Social. n. ${ }^{\circ} 178$ Enero 1998. Pp. $175-230$

PEIRÓ, J.M. (1990) Organizaciones: nuevas perspectivas psicosociológicas. Barcelona. Biblioteca Universitaria de Ciencias Sociales. Serie Maior. PPU.

PEIRO', J.M.Y PRIETO. F. (1989) Telematics and Organizational Processes. Trabajo presentado al Symposium sobre Telematics and Work, Bad Homburg, R.F.A. Abril 1989.

PEIRÓ, J.M.Y RAMOS, J. (Dirs.) (1994) Intervención Psicosocial en las Orgonizociones. Barcelona. PPU.

PERETTI. J.Y VACHETTE. J.L (1986) Audit Social. Paris. Les Editions d'Organisation.

PEREZ QUINTANA, F. (1987) Evaluoción Organizocional de un Hospital, Tesis Doctoral, Universidad de la Laguna. 
PÉREZ-VELASCO V.M.Y FERNÁNDEZ-RÍOS, M. (1985) La Evaluación Organizacional. Revisto de Psicología del Trabaja y de las Organizaciones. Vol, I. n I. Pp. 18 -35.

PERROW, C. (1970) Organizational Analysis.: A sociological view. Belmont, Calif; Brooks/Cole. (Trad. México: CECSA, 1972).

PETERS, T.J. \& WATERMAN, R.H.J. 1982. In search of excellence. New.York Harper \& Row. (Trad. Plaza \& Janés. 1984)

PRIETO, F. (1987) La innovación tecnológica en la comunicación: Nuevas perspectivas de sus efectos sobre dimensiones psicosociales de la conducta humana y organizacional. Informoción Psicológica, pp. 21 -24

PRITCHARD, R.D. (1992) Organizational productivity. In Dunnette, M. Y Hough LM. (Eds.). Handbook of industrial and organizational psychology. Vol 3, 2nd ed. Palo Alto: Consulting Psychologist Press.

PUGH. D.S. Y PHEYSEY, D.C. (1972) A comparative administration model. In Negandhi (edit) Modern Organizational theory: contextuol, environmental and sociocultural variables. Kent. O.H. Kent, State University Press.

QUINN, R.F.Y ROHRBAUGH. J. (1983) A spatial model of effectiveness criteria: towards a competing values approach to organizational analysis. Management Science, 29 (3). 363 -377 .

QUIJANO. S. D. DE (1993) La Psicología Social en los Organizaciones: Fundamentos. Barcelona Biblioteca Universitana de Ciencias Sociales. PPU.

ROUSSEAU, D.M. (1983) Technology in organizations: A constructive review and analytic framework. In Seashore, S.E. Lawler. E.E., Mirvis P.H.Y Cammann C. (Edit): Assessing Organizational Change. Nueva York Wiley.

SÁNCHEZ I.C. (1992a) Foctores componentes y determinantes de la estructura y la efectividod organizacional desde una perspectiva contingente. Tesis Doctoral. Universidad Autónoma de Madrid.

SÁNCHEZ, J.C. (1992b) Qué significa hoy ser una empresa eficaz para los directivos españoles. Aedipe, septiembre 19-26.

SCARPELLO, V.G. Y LEDVINKA, J. (1988) Personnel/Human resource management: environments and functions. Boston: Pws.Kent.

SCHODERBECK. CH. J., SCHODERBECK. P.D., KEFALAS, A.G. (1980) Manogement Systems: Conceptual considerations. Business Publications Inc.

SINGER M.G. (1990) Human resource management Boston: Pws-Kent

THOMASON, G. (1988) A textbook of human resource management Londres: Institute of Personnel Management.

THOMSON, j.D. (1967) Orgonization in Action. Nueva York. McGraw Hill.

212 THOMPSON, A.A.Jr. Y STRICKLAND A.J.III (1994) Dirección y Administración Estratégicas. Conceptos, cosos y lecturas. Argentina. Addison-Wesley lberoamericana

TYSON, S. Y YORK, A. (1986) Personnel manogement New York: William Heineman Limited. (Trad. México: Editorial Trillas. 1989)

VAN DE VEN, HA. Y FERRY, D.L (1980) Measuring and assessing organizations. Nueva York Wiley \& Sons.

VISAUTA, B. (1986) Modelos Cousales. Técnicos de Investugoción Socol. Barcelona. Editorial Hispano Europea S.A.

VECIANA, J.M. (1981) La eficacia de las organizaciones. Alta Dirección, Vol. 96 
WERTHER, W.B. Y DAVIS, J.K. (1985) Personnel management and human resources. New York: McGraw-Hill. (Trad. México: McGraw-Hill, 1987)

WOODWARD, J. (1958) Management and technology, London: H.M.: Stationary Office.

WOODWAR D. J. (1965) Industrial Organization: theory and proctice. Oxford, University Press.

YODER, D.Y HENEMAN, H.G. (1977) Handbook's of personnel and industrial relations. Washington: Bureau of National Affairs (BNA). 
Série

Investigação

Coimbra

Imprensa da Universidade

2000 